\title{
Iodine nutrition and toxicity in Atlantic cod (Gadus morhua) larvae
}

Copepods as feed promote better growth and development in marine fish larvae than rotifers. However, unlike rotifers, copepods contain several minerals such as iodine (I), at potentially toxic levels. Iodine is an essential trace element and both under and over supply of I can inhibit the production of the I containing thyroid hormones. It is unknown whether marine fish larvae require copepod levels of I or if mechanisms are present that prevent I toxicity. In this study, larval Atlantic cod (Gadus morhua) were fed rotifers enriched to intermediate (26 mg I kg ${ }^{-1}$ dry weight; MI group) or copepod (129 mg I kg ${ }^{-1}$ DW; HI group) I levels and compared to cod larvae fed control rotifers (0.6 mg I kg ${ }^{-1} \mathrm{DW}$ ). Larval I concentrations were increased by 3 (MI) and 7 (HI) fold compared to controls during the rotifer feeding period. No differences in growth were observed, but the HI diet increased thyroid follicle colloid to epithelium ratios, and affected the essential element concentrations of larvae compared to the other groups. The thyroid follicle morphology in the HI larvae is typical of colloid goitre, a condition resulting from excessive I intake, even though whole body I levels were below those found previously in copepod fed cod larvae. This is the first observation of dietary induced I toxicity in fish, and suggests I toxicity may be determined to a greater extent by bioavailability and nutrient interactions than by total body I concentrations in fish larvae . Rotifers with $0.6 \mathrm{mg} \mathrm{I} \mathrm{kg}^{-1} \mathrm{DW}$ appeared sufficient to prevent gross signs of I deficiency in cod larvae reared with continuous water exchange, while modelling of cod larvae versus rotifer I levels suggests that optimum I levels in rotifers for cod larvae is $3.5 \mathrm{mg} \mathrm{I} \mathrm{kg}^{-1} \mathrm{DW}$. 
2

3

4

5 1. National Institute of Nutrition and Seafood Research (NIFES), PO Box 2029, NO-5817

6 Bergen, Norway

7 2. Department of Biology, High Technology Centre, University of Bergen, N-5020 Bergen,

8 Norway

9 3. Institute of Marine Research, Austevoll Research Station, NO-5392 Storebø, Norway

10 4. Nofima AS, NO-6600 Sunndalsøra, Norway

11

12

13

14

15

16

17

18

19

20

21

22

23

24

* Present address; Norsildmel AS, Kjerreidviken 16, NO-5141 Fyllingsdalen, Norway

\section{Corresponding Author}

Dr Kristin Hamre

National Institute of Nutrition and Seafood Research (NIFES), PO Box 2029, 5817 Bergen

Telephone: +47 48185034

Fax: +47 55905299

E-mail: kha@nifes.no 


\section{Abstract}

26 Copepods as feed promote better growth and development in marine fish larvae than rotifers.

27 However, unlike rotifers, copepods contain several minerals such as iodine (I), at potentially 28 toxic levels. Iodine is an essential trace element and both under and over supply of I can 29 inhibit the production of the I containing thyroid hormones. It is unknown whether marine 30 fish larvae require copepod levels of I or if mechanisms are present that prevent I toxicity. In 31 this study, larval Atlantic cod (Gadus morhua) were fed rotifers enriched to intermediate (26 $32 \mathrm{mg} \mathrm{I} \mathrm{kg}{ }^{-1}$ dry weight; MI group) or copepod (129 mg I kg-1 DW; HI group) I levels and 33 compared to cod larvae fed control rotifers $\left(0.6 \mathrm{mg} \mathrm{I} \mathrm{kg}^{-1} \mathrm{DW}\right)$. Larval I concentrations were 34 increased by 3 (MI) and 7 (HI) fold compared to controls during the rotifer feeding period. No 35 differences in growth were observed, but the HI diet increased thyroid follicle colloid to 36 epithelium ratios, and effected the essential element concentrations of larvae compared to the 37 other groups. The thyroid follicle morphology in the HI larvae is typical of colloid goitre, a 38 condition resulting from excessive I intake, even though whole body I levels were below 39 those found previously in copepod fed cod larvae. This is the first observation of dietary 40 induced I toxicity in fish, and suggests I toxicity may be determined to a greater extent by 41 bioavailability and nutrient interactions than by total body I concentrations in fish larvae. 42 Rotifers with $0.6 \mathrm{mg} \mathrm{I} \mathrm{kg}^{-1} \mathrm{DW}$ appeared sufficient to prevent gross signs of I deficiency in 43 cod larvae reared with continuous water exchange, while modelling of cod larvae versus 44 rotifer I levels suggests that optimum I levels in rotifers for cod larvae is $3.5 \mathrm{mg} \mathrm{I} \mathrm{kg}^{-1} \mathrm{DW}$. 45

46 Keywords: Cod larvae, Rotifers, Iodine, Iodide, Thyroid, Colloid goitre 


\section{$47 \quad 1$ Introduction}

48 Iodine (I) is essential for vertebrates where it is utilised by the thyroid follicles to produce I 49 containing thyroid hormones, thyroxine $\left(\mathrm{T}_{4}\right)$ and tri-iodothyronine $\left(\mathrm{T}_{3}\right)$ (Sutija and Joss, 50 2005). Iodine deficiency can lead to thyroid enlargement, termed goitre (Beckett et al., 1993;

51 Vanderpas, 2006; Maier et al., 2007), and alter circulating thyroid hormone levels and ratios 52 (Ruz et al., 1999). These changes are regarded as part of a compensation mechanism. Thyroid 53 enlargement increases the capacity for thyroid hormone production, while changes in thyroid 54 hormones levels and ratios normally favour an increase or maintenance in the circulating 55 levels of the active form, $\mathrm{T}_{3}$, at the expense of the largely inactive $\mathrm{T}_{4}$ (Vanderpas, 2006). 56 Paradoxically, excessive I intake can also negatively affect thyroid hormone production and 57 produce goitre, termed I or colloid goitre (Vanderpas, 2006; Xu et al., 2006; Yang et al., 2006; 58 Franke et al., 2008). This effect is called the Wolff-Chaikoff phenomenom (Wolff and 59 Chaikoff, 1948) and probably occurs because concentrations of iodinated lipids in thyroid 60 follicles increases linearly with available I (Pereira et al., 1990), and these iodinated lipids can 61 inhibit the $\mathrm{H}_{2} \mathrm{O}_{2}$ production required for thyroid hormone synthesis (Ohayon et al., 1994; 62 Panneels et al., 1994).

63

Thyroid hormones influence gene expression in virtually all tissues and play important roles in mediating cellular metabolism and normal development (Soldin, O'Mara and Aschner, 2008). When compensation mechanisms cannot maintain thyroid hormone homeostasis numerous metabolic and development processes can be negatively affected. For example, decreased growth, mental retardation, reduced egg hatchability, increased mortality, and decreased fertility have been observed in terrestrial vertebrates fed insufficient (Potter et al., 1982; Ferri et al., 2003; Sancha et al., 2004; Vanderpas, 2006; Robertson, Friend and King, 2008; Dong et al., 2011) or excessive I (Paulikova et al., 2002; Baker, Parr and Augspurger, 2003; Baker, 2004).

Little is known about I nutrition or toxicity in fish. Inadequate I nutrition may be prevalent in the larvae of numerous marine fish species raised in captivity. For example, feeding Senegalese sole (Solea senegalensis) larvae I enriched rotifers and Artemia prevented the development of goitre and increased growth and survival (Ribeiro et al., 2011; Ribeiro et al., 2012), cod larvae survival increased when fed I and selenium enriched rotifers (Hamre et al., 2008a), and improved growth and survival in Pacific threadfin (Polydactylus sexfilis) larvae was linked to higher levels of $\mathrm{I}$ in the form of iodide $\left(\mathrm{I}^{-}\right)$versus iodate $\left(\mathrm{IO}_{3}{ }^{-}\right)$in the rearing 
81 water (Witt et al., 2009). Additional I supplementation may improve growth and development 82 in marine fish larvae because their requirements may mirror the higher levels of I found in 83 their natural feed, copepods, versus the levels found in rotifers and Artemia commonly used 84 as live feed in captivity. For example, rotifer I contents $\left(0.6-8 \mathrm{mg} \mathrm{kg}^{-1}\right.$ dry weight) are 6 to 85600 fold lower than copepod levels which range from 50 - $350 \mathrm{mg} \mathrm{kg}^{-1} \mathrm{DW}$ (Hamre et al., 86 2008b; Moren, Sloth and Hamre, 2008). Cod larvae fed copepods, like most marine fish 87 larvae, grow and develop better than when fed rotifers (Imsland et al., 2006; Busch et al., 88 2010; Koedijk et al., 2010). This has been linked to differences in the nutritional content 89 between rotifers and copepods, particularly the differences in fatty acid profiles (Rainuzzo, 90 Reitan and Olsen, 1997; Rodriguez et al., 1997; Park et al., 2006), but may also be related to 91 the difference in mineral contents, of which I is the most extreme (Hamre et al., 2008b).

92 While several studies (Hamre et al., 2008a; Penglase et al., 2010) have indicated that I 93 nutrition may be a critical determinate for thyroid hormone levels, ratios and survival in cod 94 larvae, currently none has shown this conclusively. The aim of this study was to conclude if 95 rotifers enriched up to copepod levels of I affect the thyroid status, health and growth of larval 96 cod. Diets consisting of control rotifers containing $0.6 \mathrm{mg} \mathrm{I} \mathrm{kg}^{-1} \mathrm{DW}$ or treatment rotifers 97 containing either $26 \mathrm{mg} \mathrm{I} \mathrm{kg}^{-1} \mathrm{DW}$ (MI+rotifers) or $129 \mathrm{mg} \mathrm{I} \mathrm{kg}^{-1} \mathrm{DW}$ (HI+rotifers) were fed 98 to cod larvae from 4 to $39 \mathrm{dph}$. The length, weight, survival, whole body mineral, thyroid 99 hormones, thyroid follicle number and volume were measured in larval cod during this rotifer 100 feeding period. Cod were reared on identical diets from 40 until 124 dph, and then sampled 101 for analysis of growth and skeletal deformities. Counter to the original hypothesis, we found 102 that cod larvae fed rotifers enriched to copepod levels of iodine displayed symptoms of iodine 103 toxicity. 


\section{Material and methods}

105

106

107

108

109

110

111

112

113

114

115

116

117

118

119

120

121

122

123

124

125

126

127

128

129

130

131

132

133

134

135

136

137

\subsection{Cod larvae rearing}

The experiment was performed at the Institute of Marine Research (IMR), Austevoll Research Station, Norway. This study was carried out within the Norwegian animal welfare act guidelines (code 750.000) at an approved facility. As this trial was assumed to be a nutrition trial based on all available studies up to the date of the trial, no specific permit was required under the guidelines. Naturally spawned and fertilised Atlantic cod eggs were obtained from in house second generation brood stock. Prior to incubation, eggs were disinfected with 200 mg L $\mathrm{L}^{-1}$ glutaraldehyde for $9 \mathrm{~min}$ at $6^{\circ} \mathrm{C}$ and eggs were incubated with a standard protocol as described in Penglase et al. (2010). Upon 100\% hatching (16 dpf, 99 day degrees), larval density in the incubators was measured via tube sampling and ranged from 2000-3000 larvae $\mathrm{L}^{-1}$. Three days post $100 \%$ hatching (dph), larvae (65 $\pm 2 \mu \mathrm{g}$ DW fish ${ }^{-1}, \mathrm{n}=2$ where $\mathrm{n}$ is a pool of 428 or 520 fish, and $4.9 \pm 0.2 \mathrm{~mm} \mathrm{fish}^{-1}, \mathrm{n}=30$ (mean $\pm \mathrm{SD}$ ), measured $5 \mathrm{dph}$ ) were transferred into the experimental tanks.

Larvae were stocked at an estimated density of 50000 larvae (120 larvae $\left.\mathrm{L}^{-1}\right)$ in each of the nine 500 L (400 L water volume) experimental tanks ( $n=3$ ), using volumes of larvae taken from incubators based on the initial larval density measurements. The larval tanks, including colour, material, water inlets, filter size, cleaning procedures and algal additions were as described previously (Penglase et al., 2010). Water inflow to each tank (temperature $8.0^{\circ} \mathrm{C}$, salinity $34.8 \pm 0.2 \%$, 20- $\mu \mathrm{m}$ sand/lamella filtered, degassed, from $160 \mathrm{~m}$ depth) started at 0.8 $\mathrm{L} \mathrm{min}^{-1}$ at larval transfer and increased over time to reach $4 \mathrm{~L} \mathrm{~min}^{-1}$ by $39 \mathrm{dph}$. The water temperature in larval tanks at transfer was $8.0^{\circ} \mathrm{C}(3 \mathrm{dph})$, and gradually increased and then maintained at $11.5^{\circ} \mathrm{C}$ from $27 \mathrm{dph}$. Oxygen saturation (75-102\%) and temperature were measured once daily in the outlet pipe of each tank. Dim light was provided continuously.

\subsection{Rotifer culture and enrichment}

Rotifers (Brachionus plicatilis. 'Cayman', adult lorica length $184 \pm 10 \mu \mathrm{m}$, width $134 \pm 11$ $\mu \mathrm{m}$ ) were batch cultured in $500 \mathrm{~L}$ tanks and washed as previously described (Penglase et al., 2011) (section 2.2.5 and 2.2.6) with the exception that algae paste (Chlorella sp., Docosa, SV12, Japan) was used as the culture feed. After washing, rotifers were enriched with either a control or treatment diet. The control enrichment was $250 \mathrm{mg}$ Ori-green (Skretting, Norway) million $^{-1}$ rotifers. The treatment enrichment (I+rotifers) was as per controls, but in addition 60 mg L ${ }^{-1}$ of sodium iodide (NaI; VWR, Belgium art. no. 27915.297) was added to the water at the start of rotifer enrichment. Ori-green was prepared to manufacturer's directions, while NaI 
was dissolved in cold tap water, prior to addition to rotifer enrichment tanks. Rotifers were enriched for $2 \mathrm{~h}$ at densities between $1000-2000 \mathrm{~mL}^{-1}$ in water (as for rotifer culturing) with continual aeration and oxygenation (oxygen saturation was kept above 80\%). After $1.5 \mathrm{~h}$ of this enrichment, an antibacterial (Pyceze, Novartis, Switzerland) was added to both control and treatment enrichment tanks at a rate of $0.2 \mathrm{ml} \mathrm{L}^{-1}$. Pyceze was used to lower rotifer bacterial numbers and thus control for any antibacterial effect of I enrichment. After enrichment, rotifers were washed, concentrated to 2000-4500 rotifers $\mathrm{mL}^{-1}$, transferred to storage tanks with aeration, and cooled rapidly $(<10 \mathrm{~min})$ to $8.5^{\circ} \mathrm{C}$. To maintain I concentrations in the I+rotifers, $60 \mathrm{mg} \mathrm{I} \mathrm{L}^{-1}$ (as NaI) was added to the treatment rotifer holding tank. Rotifers samples for element analysis were collected from rotifer storage tanks on 4 separate days during the larvae feeding trial. Rotifers were collected on $62 \mu \mathrm{m}$ mesh, washed for 5 min with $12^{\circ} \mathrm{C}$ saltwater, placed in $25 \mathrm{~mL}$ containers and stored at $-20^{\circ} \mathrm{C}$.

\subsection{Larval cod feeding trial}

The feeding trial started at $4 \mathrm{dph}$, using rotifers as prepared in section 2.2. Larvae were fed control or I+rotifers (HI+rotifers) or a mixture of both (80:20, control:I+, MI+rotifers). Each tank received increasing quantities of rotifers with time, starting from 3.5 million rotifers $\operatorname{tank}^{-1}$ day $^{-1}$ at $4 \mathrm{dph}$ increasing to 6 million rotifers $\operatorname{tank}^{-1}$ day $^{-1}$ by $39 \mathrm{dph}$. The same quantity of rotifers was fed to each tank, and larvae were assumed to be fed to satiation. The rotifers were fed daily to larvae in two batch feedings of equal rotifer quantity at 10:00 and 15:00. Rotifers were poured gently into larval tanks in a circular motion to ensure even rotifer distribution and minimal larvae disturbance. Control larvae and HI+larvae were fed only control or treatment rotifers respectively. The MI+larvae were fed I+ and control rotifers at 10:00, and only control rotifers at 15:00 resulting in the overall feeding ration consisting of 80:20 control: I+rotifers.

For later analysis of skeletal deformities, fish were reared on identical diets from 40 to 124 dph. Larvae were co-fed Artemia (OK performance cysts, INVE, Belgium) and rotifers from 40-44 dph. Both Artemia and rotifers were enriched with Ori-green as per directions. Fish were fed only Artemia from 45-68 dph, co-fed Artemia and formulated diet (AgloNorse-EX1, Trofi, Tromsø, Norway) from 69-91 dph. Only formulated feed was fed from 92 dph (EX1; 92-94 dph, EX1 and 2; 95-103 dph, EX2; 104-115 dph, EX3; 116-124 dph). Formulated feed was administered continuously for 24 hrs day $^{-1}$ by belt feeders. Flow rate was increased from $4 \mathrm{~L} \mathrm{~min}^{-1}$ at $30 \mathrm{dph}$ to $8 \mathrm{~L} \mathrm{~min}^{-1}$ at $108 \mathrm{dph}$, while water current speed in tanks was minimized by letting water enter through a $32 \mathrm{~mm}$ diameter inlet tube. Along with the increased water 
173 flow rate, oxygen saturation (64-96\%) was maintained by removal of fingerling cod when 174 required.

\subsection{Sampling}

177 Larvae were sampled for weight and length at 5, 9, 19, 30, and $124 \mathrm{dph}$, element and thyroid 178 hormone analysis at 5, 9, 19 and $30 \mathrm{dph}$, thyroid follicle morphology at 19, 30 and 37 dph and for analysis of skeletal deformities at $124 \mathrm{dph}$. All fish were euthanised with an overdose of tricaine methane sulfonate (MS 222) upon sampling.

182 Larvae sampled for weight, minerals and thyroid hormones were collected on mesh (62 $\mu \mathrm{m})$, 183 briefly rinsed with $\mathrm{ddH}_{2} \mathrm{O}$, and patted dry from underneath with paper towel. Larvae were then placed in pre weighed tubes and frozen immediately in liquid nitrogen and stored at $-80^{\circ} \mathrm{C}$ until analysis. All tubes were then reweighed to determine sample wet weights. Tubes sampled for weight determination were thawed and larvae were counted ( $n=20-100)$ to determine wet weight per larvae. Dry weight was determined from dry matter, which in turn was determined from tubes weighed before and after lyophilising. The standard length of the larvae was measured according to Hamre et al. (2008a) on 10 larvae tank $\mathrm{k}^{-1}$. Larval densities in tanks were measured at $30 \mathrm{dph}$ as described by Penglase et al. (2010).

Larvae for thyroid follicle (3 fish $\operatorname{tank}^{-1}$ ) were selectively sampled to be similar in length, thus representing similar levels of morphological development (Sæle and Pittman, 2010). Larvae were placed in individual tubes containing $1 \mathrm{ml}$ of $4 \%$ paraformaldehyde in PBS buffer at $\mathrm{pH}$ 7.2. Samples were left overnight and then transferred to separate tubes containing $70 \%$ 195 ethanol, where they remained at $4^{\circ} \mathrm{C}$ until embedding. For analysis of skeletal deformities, cod juveniles ( $124 \mathrm{dph}, \mathrm{n}=50$ per tank) were measured for length and weight, frozen flat and subsequently stored in individual labelled plastic bags at $-20^{\circ} \mathrm{C}$ until analysis. Survival in one $\mathrm{HI}+$ tank decreased to zero prior to this sampling, so data represents the mean $\pm \mathrm{SD} n=2$ for the $\mathrm{HI}+$ fish at $124 \mathrm{dph}$.

\subsection{Analytical methods}

\subsubsection{Mineral analysis}

203 Samples for analysis of total I were digested under alkaline conditions using tetra methyl 204 ammonium hydroxide $\left(\left(\mathrm{CH}_{3}\right)_{4} \mathrm{NOH}\right.$, Tamapure-AA, Tama chemicals, Japan) and then analysed with ICP-MS (Agilent 7500 series, USA) as described by Julshamn, Dahl and Eckhoff (2001) with cod muscle (BCR-422, Belgium) used as the standard reference material. 
$208 \% \mathrm{HNO}_{3}$ Suprapur $^{\circledR}$, Merck, Germany) and hydrogen peroxide (30\% $\mathrm{H}_{2} \mathrm{O}_{2}$, Merck, 209 Germany), in a microwave (Ethos 1600, Milestone, USA) as described by Julshamn et al. 210 (2004). The samples were then analysed with ICP-MS along with blanks and standard 211 reference material as described previously (Julshamn et al., 2004), with modifications to the 212 mass of Mn (Mass 55) and Pb (Mass 208) measured. The standard reference materials used 213 (NIST-SRM 1566, Oyster tissue, USA; TORT-2, NRC, lobster hepatopancreas, Canada) had 214 similar concentrations of minerals as the samples analysed.

215 2.5.2 Thyroid hormone analysis

216 Thyroid hormones extraction from larvae was carried out according to Einarsdottir et al. 217 (2006) with some modifications. Approximately $500 \mathrm{mg}$ WW of larvae (440 to $630 \mathrm{mg}$ ) was 218 homogenised (Precellys 24, Bertin technologies, France) in $1 \mathrm{ml}$ of ice-cold methanol 219 (Sigma-Aldrich, Germany), and then stored over night at $-20^{\circ} \mathrm{C}$. Samples were then 220 centrifuged (30 min, $3000 \mathrm{rpm}, 4{ }^{\circ} \mathrm{C}$ ) and the supernatant removed from the pellet. This 221 extraction procedure was then repeated on the pellet twice more. Nitrogen was used to dry the 222 supernatant of methanol. Lipids were removed from samples by modified Folch extraction. To eliminate any lipid in samples, the dried extracts were dissolved in barbital buffer $(0.1 \mathrm{M} \mathrm{pH}$ 8.6), methanol and chloroform (1:1:2). The aqueous phase containing $T_{4}$ and $T_{3}$ was transferred to a fresh tube, evaporated with nitrogen and frozen at $-20^{\circ} \mathrm{C}$ until use. To estimate extraction efficiency, $\approx 1000 \mathrm{cpm}$ of $\left[{ }^{125} \mathrm{I}\right]-\mathrm{rT} \mathrm{T}_{3}$ (NEX109, Perkin Elmer, USA) were added to the homogenates after homogenisation. The extraction efficiency ranged between 71 to $81 \%$. The $T_{4}$ and $T_{3}$ content were determined by radioimmunoassay using an external standard curve according to Einarsdottir et al. (2006), and further corrected for the extraction efficiency of each sample. Larval $\mathrm{T}_{3}$ contents were also reanalysed by a DELFIA ${ }^{\circledR} \mathrm{T}_{3} \mathrm{Kit}$ (PerkinElmer, Turku, Finland) according to manufacturer's instructions.

\subsubsection{Thyroid follicle histology}

Larvae were dehydrated in an increasing gradient of ethanol and embedded in Technovit 7100 as per directions (Heraeus Kulzer, Wehrheim, Germany). The resin blocks were then sectioned into $5 \mu \mathrm{m}$ thick slices, and every second section was placed on a slide and stained with toluidine blue. The follicle number within the pharyngeal region was counted and the area of epithelium and colloid were measured for each larvae (2 larvae $\operatorname{tank}^{-1}$ at 19 and $30 \mathrm{dph}, 1$ larvae $\operatorname{tank}^{-1}$ at $37 \mathrm{dph}$ ) at $200 \times$ magnification using a microscope and computer assisted program CAST-grid version 2 (Olympus, Albertslund, Denmark) according to Saele et al.

241 (2003). The colloid and epithelium volume were calculated using area and width of sections, 
and skipped sections were assumed to have the same volume as that measured on the

243 preceding section. Larval sections were also scanned for evidence of thyroid follicles in the 244 kidneys, as has been observed for some other fish species such as common carp (Cyprinus carpio) (Geven et al., 2007), but none were observed.

\subsubsection{Radiography}

248 The radiographic imaging and analysis of skeletal deformities was performed as described 249 previously (Penglase et al., 2010) with skeletal deformities and degree of deformities classified according to Baeverfjord et al. (undated). Briefly, radiographic images were visually examined for any skeletal pathology, and deviations from normal were recorded. Deviations were classified in axial deviations, vertebral deviations and head deformities, and further classified into sub categories and degrees of severity.

\subsection{Calculations}

Larval survival was adjusted using a linear individual probability timeline for each tank to calculate the probable survival of sampled larvae had they remained in the tanks until density measurements at $30 \mathrm{dph}$, using the following equation;

Estimated survival of sampled larvae at time point $\left.\left.\mathrm{Y}=100-\left(\left((100-\mathrm{S}) / \mathrm{T}_{1}\right) *\left(\mathrm{~T}_{1}-\mathrm{T}_{2}\right)\right) / 100\right) * \mathrm{X}\right)$ where $\mathrm{S}$ is the measured survival \% at $30 \mathrm{dph}, \mathrm{T}_{1}$ equals the time period in days from the start (5 dph) and end (30 dph) survival measurements (25 d), $\mathrm{T}_{2}$ equals the number of days post $100 \%$ survival (trial start) and $\mathrm{X}$ equals the number of larvae sampled at time point $\mathrm{Y}$. This equation was used to produce two numbers, one for the sampling at $9\left(\mathrm{~T}_{2}=4\right)$ and one at 19 $\left(\mathrm{T}_{2}=14\right) \mathrm{dph}$, and along with the number of larvae sampled on day 30, were added to the larvae measured in tanks from density measurements taken after sampling at $30 \mathrm{dph}$. Specific growth rates (SGR) of cod larvae were calculated with the following equation SGR $=\left(\mathrm{e}^{\wedge}\left(\left(\ln W_{1}-\ln W_{0}\right) /\left(\mathrm{t}_{2}-\mathrm{t}_{1}\right)\right)-1\right) \times 100$ where $W_{0}$ and $W_{1}$ are the initial and final dry weights (tank means) respectively, and $t_{2}-t_{1}$ is the time interval in days between age $t_{1}$ and $t_{2}$ (Ricker, 1958). Fulton's condition factor (FC) was calculated using FC = Weight (g)*100/Length(cm) ${ }^{3}$.

271 The I concentration ratio (CR) between larvae and feed was CR = Larval I content ( $\mathrm{mg} \mathrm{kg}^{-1}$ 272 DW)/rotifer I content ( $\left.\mathrm{mg} \mathrm{kg}^{-1} \mathrm{DW}\right)$.

\subsection{Data analyses}

275 Statistica software (Statsoft Inc., 2008, Tulsa, USA, Ver.9) was used for statistical analysis of

276 data except when GraphPad Prism (GraphPad Software, San Diego, CA, USA, Ver. 5) was 
277 used to model fit the I concentration of cod larvae versus rotifers, and on data from $124 \mathrm{dph}$, 278 as the loss of one replicate in the HI larvae group prevented ANOVA analysis between all 279 three groups. Data analysed with Statistica were checked for homogeneity of variances using 280 Levene's test before having significance tested with one-way ANOVA followed with Fisher's 281 least significant difference (LSD) homogeneity post-hoc test at each time point. Data with 282 significantly different variance between treatments according to Levene's test $(\mathrm{p}<0.05)$ was 283 log transformed before analysis. As the density of cod larvae has a large effect on growth 284 (Koedijk et al., 2010), growth data during the larval stage was analysed with ANCOVA with 285 the final larval density in tanks included as a continuous predictor. Data from 124 dph were 286 analysed using regression, and tested against the null hypothesis that rotifer I content had no 287 effect on outcome. Differences among means were considered significant at $\mathrm{p}<0.05$. 


\section{Results}

2893.1 Cod larvae growth

290 No statistically significant differences in cod larvae length $(\mathrm{p}>0.08)$ or dry weight $(\mathrm{p}>0.25)$

291 occurred between treatments, although high variation between tanks may have masked effects

292 (Fig. 1). On average, cod larvae grew from $4.9 \pm 0.2 \mathrm{~mm}$ to $6.8 \pm 0.5 \mathrm{~mm}$ in length, and 0.065 $293 \pm 0.002 \mathrm{mg}$ to $0.27 \pm 0.07 \mathrm{mg} \mathrm{fish}^{-1}$ in dry weight from 5 to $30 \mathrm{dph}$ (Fig. 1), representing a 294 specific growth rate of $6.3 \%$ day $^{-1}$ during this period.

\subsection{Survival}

296 There were no statistical differences ( $>>0.39$ ) in the cod larval survival adjusted for sampled 297 larvae (see section 2.6) between treatments at 30 dph which were $28 \pm 2,39 \pm 20$ and $30 \pm 15$ 298 \% for controls, MI and HI groups respectively, while the average for all groups was $32 \pm 13$ 299 \%. Survivals based solely on densities in tanks at 30 dph without taking into account sampled 300 larvae were $12 \pm 2,19 \pm 12$ and $12 \pm 10 \%$ for controls, MI and HI groups respectively.

301

3.3 lodine and other essential element concentrations in rotifers and cod larvae Control rotifers contained $0.60 \pm 0.33 \mathrm{mg} \mathrm{I} \mathrm{kg}^{-1} \mathrm{DW}$ while HI+rotifers contained $129 \pm 101$ mg I kg-1 DW (Table 1). Whole body I levels in cod larvae were significantly different between groups ( $\mathrm{p}<0.01$, Fig. 2). Cod larvae ( $5 \mathrm{dph}$ ) had a starting concentration of $4.0 \pm 0.3$ mg I kg ${ }^{-1} \mathrm{DW}$. Between 9 and $30 \mathrm{dph}$ average I concentrations were $1.6 \pm 0.3 \mathrm{mg} \mathrm{I} \mathrm{kg}^{-1} \mathrm{DW}$ for control larvae, while MI larvae had 3 fold higher levels ( $4.9 \pm 2.4 \mathrm{mg} \mathrm{I} \mathrm{kg}^{-1} \mathrm{DW}$ ), and $\mathrm{HI}$ larvae 7 fold higher levels $\left(11.0 \pm 3.3 \mathrm{mg} \mathrm{I} \mathrm{kg}^{-1} \mathrm{DW}\right)$ than controls. Other element concentrations were also affected by treatment in both rotifers and cod larvae. HI+rotifers contained less Fe and Mn than controls (Table 1), while HI larvae contained more Mn, Fe and $\mathrm{Cu}$ than controls and MI larvae at one or more time points (Fig. 2b-c, e). Both $\mathrm{HI}$ and MI larvae contained higher levels of Co than controls (Fig. 2d), while larval Zn and Se concentrations were unaffected by treatment (Fig. 2f-g). Rotifer macro mineral concentrations were unaffected by treatment (Table 1), but increased levels of $\mathrm{Ca}$ and $\mathrm{Mg}$, and lower levels of $\mathrm{P}$ and $\mathrm{K}$ were observed in $\mathrm{HI}$ larvae in comparison to controls and/or MI larvae during the rotifer feeding period (Fig. 3).

\subsection{Iodine concentration in cod larvae versus rotifers}

The rate of increase in cod larvae I concentrations decreased as dietary I levels (rotifer I concentration) increased, and thus the I concentration ratio between cod larvae and rotifers displayed a negative trend (Fig 4; $<<0.01$ ). The age of the cod larvae did not effect their I concentration ratio $(\mathrm{p}=0.96)$. The model predicts that the ratio of $\mathrm{I}$ in cod larvae versus rotifers equals 1 when rotifers have $3.5 \mathrm{mg} \mathrm{I} \mathrm{kg}^{-1} \mathrm{DW}$ (Fig. 4). 
3223.5 Thyroid hormones and thyroid follicle morphology

323 There were no differences in thyroid hormone levels or ratios between treatments (Fig. 5).

324 Data was normalised to aid interpretation, as $\mathrm{T}_{3}$ results were higher than obtained previously 325 (Penglase et al., 2010) and the high result was validated by the analysis of $\mathrm{T}_{3}$ with a second 326 method (see methods). The total volume of thyroid follicle was 1.3 fold lower and the total 327 epithelium volume was 1.4 fold lower per fish in HI versus MI larvae, but not controls, at 30 328 dph (Fig. 6a, c). The thyroid follicle colloid to epithelium ratio was higher in HI larvae than 329 controls at 19 (1.7 fold) and 37 (1.8 fold) dph, while MI larvae did not differ from controls 330 (Fig. 6d). No statistically significant differences were observed between groups in colloid 331 volume or total number of thyroid follicles (Fig. 6b, e). Images of thyroid follicle sections 332 from control and HI larvae at $37 \mathrm{dph}$ are shown in figure 7.

333 3.6 Weight, length, condition factor and rate of skeletal deformities at $124 \mathrm{dph}$

334 There were no significant differences in the weights (average; $2.50 \pm 0.19 \mathrm{~g}$ ), lengths (6.14 \pm $3350.16 \mathrm{~cm})$ or condition factors $(1.05 \pm 0.03)$ between groups at $124 \mathrm{dph}$ (Table 2, $\mathrm{n}=400)$. Neck 336 axis angle became closer to normal (180 \pm 3 degrees) with increasing I levels in rotifers, but 337 there were no differences in any of the other skeletal deformity measurements (Table 2). 338 
340 The hypothesis of this study was that commercially reared cod larvae fed rotifers would 341 benefit from increased dietary I. The bases for this hypothesis were, one; rotifer I concentrations are often at the lower end or below juvenile/adult fish requirements (NRC, 2011), two; rotifers have 6 - 600 fold lower concentrations of I than copepods (Hamre et al., 2008b), the natural feed of cod larvae (Thompson and Harrop, 1991), three; cod larvae have better growth and development when fed copepods versus rotifers (Busch et al., 2010; Koedijk et al., 2010), four; I levels in copepod fed cod larvae are higher than rotifer fed cod larvae (Busch et al., 2010), and five; increased growth and/or survival has been observed in larval stages of several marine fish species fed or reared in environments with increased levels of bioavailable I (Hamre et al., 2008a; Witt et al., 2009; Ribeiro et al., 2011; Ribeiro et al., 2012).

However, in contrast to the hypothesis, the increased thyroid follicle colloid to epithelium $(\mathrm{C} / \mathrm{E})$ ratio observed in this study indicates that I toxicity occurred in cod larvae fed rotifers with $129 \mathrm{mg} \mathrm{I} \mathrm{kg}^{-1} \mathrm{DW}$. This observation purely in relation to the I level is not unexpected. A high $\mathrm{C} / \mathrm{E}$ ratio in thyroid follicles is a classic symptom of I induced toxicity termed I (Baker, 2004) or colloid goitre, and occurs in mice at dietary I concentrations 10 fold higher than requirements with increasing severity developing with increasing I ingestion rates (Yang et al., 2006). What is interesting is that despite copepods containing $50-350 \mathrm{mg} \mathrm{I} \mathrm{kg}^{-1} \mathrm{DW}$ (Solbakken et al., 2002; Hamre et al., 2008b), cod larvae have either similar or lower thyroid follicle C/E ratios when fed copepods compared to rotifers (Grøtan, 2005). Furthermore, I concentrations observed in cod larvae fed natural zooplankton (29 $\mathrm{mg} \mathrm{I} \mathrm{kg}^{-1} \mathrm{DW}$ at $27 \mathrm{dph}$; (Busch et al., 2010)) were 2.2 fold higher than the highest level observed in the current study (HI larvae, $30 \mathrm{dph} ; 13 \pm 4 \mathrm{mg} \mathrm{I} \mathrm{kg}{ }^{-1} \mathrm{DW}$ ). Thus it appears that high I concentrations in copepods do not induce morphological changes in thyroid follicles consistent with I toxicity, but do appear to be effectively transferred from copepods to fish larvae upon consumption.

It is possible that copepods do not induce I toxicity in fish larvae due to nutrient interactions. For example, I toxicity can be prevented by the simultaneous presence of the bromine anion (Br-) in animals ranging from chicks (Gallus gallus) (Baker, Parr and Augspurger, 2003) to Artemia (S. Penglase et al., unpublished data). The exact mechanism for this $\mathrm{Br}^{-} / \mathrm{I}^{-}$interaction is still unknown, but it has been demonstrated that $\mathrm{Br}^{-}$decreases iodide accumulation in the thyroid follicles and increases I excretion via the kidneys in rats (Pavelka, 2004). Although the bromide concentrations in whole copepods and rotifers are unknown, we speculate that copepods have relatively high levels of bromide reflecting the high levels found in other 
373 marine organisms, and this bromide helps prevent I toxicity in fish larvae. In the marine 374 ecosystem, bromine is naturally found at similar high concentrations as I in seaweed 375 (Romaris-Hortas, Moreda-Pineiro and Bermejo-Barrera, 2009), adult fish (Arafa et al., 2000; 376 Wan et al., 2010), and as part of the hard chitin structures of crustaceans such as crabs (Cribb 377 et al., 2009; Schofield et al., 2009) and copepods (Perry, Grime and Watt, 1988).

378 Thyroid hormone levels and ratios were similar between cod larvae groups, and this is 379 probably due to the compensatory changes observed in the thyroid follicles. For example 380 pathological changes of over $70 \%$ in thyroid gland morphology have been observed in dogs 381 (Canis lupus familiaris) with little change in circulating TH levels (Graham, Refsal and 382 Nachreiner, 2007), and significant changes in fish thyroid follicle morphology with little 383 change in thyroid hormone levels have also been reported for fish (Hawkyard et al., 2011; 384 Morris et al., 2011).

385 Few differences were found between the control and MI larvae groups, with the exception of 386 whole body I concentrations. The increased whole body I content of cod larvae demonstrates 387 the effective transfer of I from the rotifers to the cod larvae. The current study differs to 388 previous studies exploring the uptake of I in fish larvae, as it attempted to ensure the ingestion 389 of graded levels of I by maintaining the I concentration in the prey organism up until the point 390 391 392 393 394 395 396 of feeding. Srivastava et al. (2012) found that I leaches rapidly from rotifers after enrichment with sodium iodide. Previous studies have found no difference in the I concentration of cod larvae fed control or I supplemented rotifers (Hamre et al., 2008a); S. Penglase et al., unpublished data), and this is probably a consequence of I leaching from rotifers in the minimum 1.5 to $2 \mathrm{~h}$ period between rotifer enrichment and feeding of the rotifers to cod larvae in these studies.

In the current study, cod larvae iodine level increases were proportionally smaller for each increase in dietary I levels; control fish were 2.7 fold higher, while MI were 5 fold lower and HI larvae were 12 fold lower in I than their respective diets. Body stores of minerals are a good indicator of status (Baker, 1986), and the decreasing level of I retention in cod larvae relative to feed I levels indicates that requirements were met at levels lower than those fed to MI larvae. Modelling of the ratio between cod larvae and rotifer I concentrations predicts that based on a ratio of $1: 1$, rotifer I concentrations of $3.5 \mathrm{mg} \mathrm{kg}^{-1} \mathrm{DW}$ meet cod larvae requirements. Both food and water contribute to the I status of adult, juvenile (Lall, 2002) and larval fish (Witt et al., 2009; Ribeiro et al., 2011). Alongside the I content in the continuously 
405

406

407

408

409

410

411

412

413

414

415

416

417

418

419

420

421

422

423

424

425

426

427

428

429

430

431

432

433

434

435

436

437

exchanging seawater (88 $\mu \mathrm{g} \mathrm{I} \mathrm{L}^{-1}$, Moren, Sloth and Hamre, 2008), the control rotifers in the current study with $0.6 \mathrm{mg} \mathrm{I} \mathrm{kg}{ }^{-1} \mathrm{DW}$ appeared to prevent any gross signs of I deficiency in cod larvae. This is at the lower end of the $0.6-1.1 \mathrm{mg} \mathrm{I} \mathrm{kg}^{-1} \mathrm{DW}$ recommended by the national research council (NRC, 2011) as the I requirements of juvenile/adult fish.

The reason that symptoms of severe I deficiency such as classic goitre have been observed in other fish studies is probably due to water parameters. Clear signs of I deficiency (goitre, decreased growth and/or decreased survival) occurred in fish larvae reared in either recirculation systems (Ribeiro et al., 2011; Ribeiro et al., 2012) or well water (Witt et al., 2009). Nitrate $\left(\mathrm{NO}_{3}{ }^{-}\right)$is goitrogenic as it competitively blocks iodide uptake by the sodium iodide symporter (Tonacchera et al., 2004), and $\mathrm{NO}_{3}^{-}$at levels commonly found in recirculation systems causes goitre in sharks (Crow et al., 1998; Morris et al., 2011). Furthermore, ozone $\left(\mathrm{O}_{3}\right)$ used as a disinfectant in recirculation systems readily oxidises bioavailable I, iodide $\left(\mathrm{I}^{-}\right)$to iodate $\left(\mathrm{IO}_{3}{ }^{-}\right)$(Sherrill, Whitaker and Wong, 2004). Dissolve iodate is presumed to have low bioavailablity for fish (Sherrill, Whitaker and Wong, 2004), and higher levels of iodate compared to iodide were correlated to poor growth and survival in well water reared pacific threadfin larvae (Witt et al., 2009). Thus in recirculation systems, the presence of high levels of goitrogens $\left(\mathrm{NO}_{3}{ }^{-}\right)$and low levels of dissolved bioavailable $\mathrm{I}\left(\mathrm{I}^{-}\right)$ may increase the dietary I requirements of fish larvae over those reared with continuous water exchange where nitrate and its precursors are continuously removed and iodide continuously replaced, such as in the current study.

Along with thyroid follicle morphology, dietary I also influenced the mineral composition of cod larvae. While most of the tested mineral concentrations in MI larvae were similar to controls, HI larvae had 10 to 25\% higher levels of $\mathrm{Ca}, \mathrm{Mg}, \mathrm{Mn}, \mathrm{Fe}$, $\mathrm{Co}$ and $\mathrm{Cu}$ and around $10 \%$ lower levels of $\mathrm{P}$ and $\mathrm{K}$ than controls at one or more time points within the rotifer feeding period. For most of the minerals, differences in levels were observed by the first sampling point ( 9 dph; 4 days of feeding on rotifers). The differences cannot be explained by the feed; the HI rotifers had $\approx 10 \%$ less $\mathrm{Mn}$ and $\mathrm{Fe}$, and no statistical differences were observed in $\mathrm{Ca}, \mathrm{Mg}, \mathrm{K}, \mathrm{P}, \mathrm{Cu}$ or Co concentrations. Hamre et al. (2008a) found that cod larvae fed increased levels of both I and Se had an 8\% increase in whole body copper levels, similar to this study. Nguyen et al. (2008) found increased or decreased copper levels (20\%) in red sea bream (Pagrus major) larvae depending on whether they were fed rotifers enriched with Mn alone or alongside Zn. While it is known that I deficiency can alter mineral distribution and homeostasis of $\mathrm{Cu}, \mathrm{Mn}, \mathrm{Fe}$ and Zn (Giray et al., 2003), to our knowledge this 
438 is the first data demonstrating that I oversupply can also effect mineral homeostasis. Although 439 there were few differences in growth or skeletal deformities observed between treatments at $440124 \mathrm{dph}$, there was a small but statistically significant improvement in the neck axis angle in 441 the HI compared to the control and MI cod groups (Table 2), and this may be linked to the 442 differences in cod mineral concentrations in the larval stage.

\section{Conclusion}

444 Iodine enriched rotifers increased the levels of I in cod larvae, although as I levels in rotifers 445 increased the increases in cod larvae I levels became proportionally smaller. Few differences 446 occurred between cod larvae reared on control diets with $0.6 \mathrm{mg} \mathrm{I} \mathrm{kg}^{-1} \mathrm{DW}$ and those reared 447 on diets with $26 \mathrm{mg} \mathrm{I} \mathrm{kg}^{-1} \mathrm{DW}$, while the I concentration ratio between cod larvae and rotifers 448 suggests cod larvae have an I requirement of $3.5 \mathrm{mg} \mathrm{I} \mathrm{kg}^{-1}$ rotifers DW. Rotifers with copepod 449 levels of I (129 mg I kg-1 DW) changed cod larvae whole body concentration of many 450 essential minerals and induced changes in thyroid follicles morphology consistent with colloid 451 goitre. The data presents one of the first observations of dietary induced I toxicity in fish, and 452 suggests that I toxicity in fish larvae may be determined to a greater extent by I bioavailability 453 and nutrient interactions than by body burdens of I.

\section{Acknowledgements}

456 This work was financed by the Norwegian Research Council (project no. 185006/S40). Thank 457 you to technical staff at IMR Austevoll and NIFES for fish husbandry, sampling help and 458 skilled analytical assistance, especially Stig Ove Utskot and Berit Solli. Thank you to Karin 459 Pittman for allowing access to equipment for thyroid follicle morphology quantification. 460 Contributions of the authors. S. P., K. H., A. N. and T.H designed the project, T. H. conducted 461 animal trials, S. P., K. H. and T. H. sampled. S. P., O.S. and S.H. analysed samples. S. P. 462 statistically analysed data. All authors contributed to manuscript writing and revision. 463 Conflicts of interest. None. 


\section{References}

Arafa, E. A., Bejey, A. M., Etwir, R. H. and Das, H. A. 2000. Determination of iodine and bromine in fish samples by radiochemical neutron activation analysis. Journal of Trace and Microprobe Techniques 18(3): 461-466.

Baeverfjord, G., Hjelde, K., Helland, S. and Lein, I. No date. Malformations in farmed fish. Guidelines for classification; II. Cod (Gadus morhua). Available at http://www.aquatour.info/FileLibrary\%5C28\%5CCod\%20diagnostic\%20manual.pdf (accessed 15 November 2012)

Baker, D. H. 1986. Problems and pitfalls in animal experiments designed to establish dietary requirements for essential nutrients. Journal of Nutrition 116(12): 2339-2349.

Baker, D. H. 2004. Iodine toxicity and its amelioration. Experimental Biology and Medicine 229(6): 473-478.

Baker, D. H., Parr, T. M. and Augspurger, N. R. 2003. Oral iodine toxicity in chicks can be reversed by supplemental bromine. Journal of Nutrition 133(7): 2309-2312.

Beckett, G. J., Nicol, F., Rae, P. W. H., Beech, S., Guo, Y. M. and Arthur, J. R. 1993. Effects of combined iodine and selenium deficiency on thyroid-hormone metabolism in rats. American Journal of Clinical Nutrition 57(2): S240-S243.

Busch, K. E. T., Falk-Petersen, I. B., Peruzzi, S., Rist, N. A. and Hamre, K. 2010. Natural zooplankton as larval feed in intensive rearing systems for juvenile production of Atlantic cod (Gadus morhua L.). Aquaculture Research 41(12): 1727-1740.

Cribb, B. W., Rathmell, A., Charters, R., Rasch, R., Huang, H. and Tibbetts, I. R. 2009. Structure, composition and properties of naturally occurring non-calcified crustacean cuticle. Arthropod Structure \& Development 38(3): 173-178.

Crow, G. L., Atkinson, M. J., Ron, B., Atkinson, S., Skillman, A. D. K. and Wong, G. T. F. 1998. Relationship of water chemistry to serum thyroid hormones in captive sharks with goitres. Aquatic Geochemistry 4(3-4): 469-480.

Dong, J., Liu, W. Y., Wang, Y., Hou, Y., Xu, H. D., Gong, J. A., Xi, Q. and Chen, J. 2011. Developmental iodine deficiency and hypothyroidism impair spatial memory in adolescent rat hippocampus: involvement of camkii, calmodulin and calcineurin. Neurotoxicity Research 19(1): 81-93.

Einarsdottir, I. E., Silva, N., Power, D. M., Smaradottir, H. and Bjornsson, B. T. 2006. Thyroid and pituitary gland development from hatching through metamorphosis of a teleost flatfish, the Atlantic halibut. Anatomy and Embryology 211(1): 47-60.

Ferri, N., Ulisse, S., Aghini-Lombardi, F., Graziano, F. M., Di Mattia, T., Russo, F. P., Arizzi, M., Baldini, E., Trimboli, P., Attanasio, D., Fumarola, A., Pinchera, A. and D'Armiento, M. 2003. Iodine supplementation restores fertility of sheep exposed to iodine deficiency. Journal of Endocrinological Investigation 26(11): 1081-1087. 
Franke, K., Schone, F., Berk, A., Leiterer, M. and Flachowsky, G. 2008. Influence of dietary iodine on the iodine content of pork and the distribution of the trace element in the body. European Journal of Nutrition 47(1): 40-46.

Geven, E. J. W., Nguyen, N.-K., van den Boogaart, M., Spanings, F. A. T., Flik, G. and Klaren, P. H. M. 2007. Comparative thyroidology: thyroid gland location and iodothyronine dynamics in Mozambique tilapia (Oreochromis mossambicus Peters) and common carp (Cyprinus carpio L.). Journal of Experimental Biology 210(22): 4005-4015.

Giray, B., Riondel, J., Arnaud, J., Ducros, V., Favier, A. and Hincal, F. 2003. Iodine and/or selenium deficiency alters tissue distribution pattern of other trace elements in rats. Biological Trace Element Research 95(3): 247-258.

Graham, P. A., Refsal, K. R. and Nachreiner, R. F. 2007. Etiopathologic findings of canine hypothyroidism. Veterinary Clinics of North America: Small Animal Practice 37(4): 617-631.

Grøtan, E. 2005. Development of pituitary and thyroid follicles of cod (Gadus morhua) larvae and early juveniles with different temperatures and diets. Department of Biology, University of Bergen. Masters Thesis (In Norwegian).

Hamre, K., Mollan, T. A., Saele, O. and Erstad, B. 2008a. Rotifers enriched with iodine and selenium increase survival in Atlantic cod (Gadus morhua) larvae. Aquaculture 284(1-4): 190-195.

Hamre, K., Srivastava, A., Rønnestad, I., Mangor-Jensen, A. and Stoss, J. 2008b. Several micronutrients in the rotifer Brachionus sp. may not fulfill the nutritional requirements of marine fish larvae. Aquaculture Nutrition 14: 51-60.

Hawkyard, M., Sæle, Ø., Nordgreen, A., Langdon, C. and Hamre, K. 2011. Effect of iodine enrichment of Artemia sp. on their nutritional value for larval zebrafish (Danio rerio). Aquaculture 316(1-4): 37-43.

Imsland, A. K., Foss, A., Koedijk, R., Folkvord, A., Stefansson, S. O. and Jonassen, T. M. 2006. Short- and long-term differences in growth, feed conversion efficiency and deformities in juvenile Atlantic cod (Gadus morhua) startfed on rotifers or zooplankton. Aquaculture Research 37(10): 1015-1027.

Julshamn, K., Dahl, L. and Eckhoff, K. 2001. Determination of iodine in seafood by inductively coupled plasma/mass spectrometry. Journal of Aoac International 84(6): 1976-1983.

Julshamn, K., Lundebye, A. K., Heggstad, K., Berntssen, M. H. G. and Boe, B. 2004. Norwegian monitoring program on the inorganic and organic contaminants in fish caught in the Barents Sea, Norwegian Sea and North Sea, 1994-2001. Food Additives \& Contaminants: Part A 21(4): 365 - 376.

Koedijk, R. M., Folkvord, A., Foss, A., Pittman, K., Stefansson, S. O., Handeland, S. and Imsland, A. K. 2010. The influence of first-feeding diet on the Atlantic cod Gadus morhua phenotype: survival, development and long-term consequences for growth. Journal of Fish Biology 77(1): 1-19. 
Lall, S. P. 2002. The minerals. In: J. E. Halver and R. W. Hardy, ed. Fish nutrition. London: Elsevier Science, 260-309.

Maier, J., van Steeg, H., van Oostrom, C., Paschke, R., Weiss, R. E. and Krohn, K. 2007. Iodine deficiency activates antioxidant genes and causes DNA damage in the thyroid gland of rats and mice. Biochimica Et Biophysica Acta-Molecular Cell Research 1773(6): 990-999.

Moren, M., Sloth, J. J. and Hamre, K. 2008. Uptake of iodide from water in Atlantic halibut larvae (Hippoglossus hippoglossus L.). Aquaculture 285(1-4): 174-178.

Morris, A. L., Hamlin, H. J., Francis-Floyd, R., Sheppard, B. J. and Guillette, L. J. 2011. Nitrate-induced goiter in captive whitespotted bamboo sharks Chiloscyllium plagiosum. Journal of Aquatic Animal Health 23(2): 92-99.

Nguyen, V. T., Satoh, S., Haga, Y., Fushimi, H. and Kotani, T. 2008. Effect of zinc and manganese supplementation in Artemia on growth and vertebral deformity in red sea bream (Pagrus major) larvae. Aquaculture 285(1-4): 184-192.

NRC 2011. Nutrient requirements of fish and shrimp. Washington: National Academy Press.

Ohayon, R., Boeynaems, J. M., Braekman, J. C., Vandenbergen, H., Gorin, Y. and Virion, A. 1994. Inhibition of thyroid Nadph-oxidase by 2-iodohexadecanal in a cell-free system. Molecular and Cellular Endocrinology 99(1): 133-141.

Panneels, V., Van den Bergen, H., Jacoby, C., Braekman, J. C., Van Sande, J., Dumont, J. E. and Boeynaems, J. M. 1994. Inhibition of $\mathrm{H}_{2} \mathrm{O}_{2}$ production by iodoaldehydes in cultured dog thyroid cells. Molecular and Cellular Endocrinology 102(1-2): 167-176.

Park, H. G., Puvanendran, V., Kellett, A., Parrish, C. C. and Brown, J. A. 2006. Effect of enriched rotifers on growth, survival, and composition of larval Atlantic cod (Gadus morhua). Journal Of Marine Science 63(2): 285-295.

Paulikova, I., Kovac, G., Bires, J., Paulik, S., Seidel, H. and Nagy, O. 2002. Iodine toxicity in ruminants. Veterinarni Medicina 47(12): 343-350.

Pavelka, S. 2004. Metabolism of bromide and its interference with the metabolism of iodine. Physiological Research 53: S81-S90.

Penglase, S., Hamre, K., Sweetman, J. W. and Nordgreen, A. 2011. A new method to increase and maintain the concentration of selenium in rotifers (Brachionus spp.). Aquaculture 315(1-2): 144-153.

Penglase, S., Nordgreen, A., van der Meeren, T., Olsvik, P. A., Sæle, Ø., Sweetman, J. W., Baeverfjord, G., Helland, S. and Hamre, K. 2010. Increasing the level of selenium in rotifers (Brachionus plicatilis `Cayman') enhances the mRNA expression and activity of glutathione peroxidase in cod (Gadus morhua L.) larvae. Aquaculture 306(1-4): 259-269.

Pereira, A., Braekman, J. C., Dumont, J. E. and Boeynaems, J. M. 1990. Identification of a major iodolipid from the horse thyroid-gland as 2-iodohexadecanal. Journal of Biological Chemistry 265(28): 17018-17025. 
Perry, C. C., Grime, G. W. and Watt, F. 1988. An X-ray analytical study of mandibles from calanus pacificus, an herbivorous copepod. Nuclear Instruments and Methods in Physics Research Section B: Beam Interactions with Materials and Atoms 30(3): 367-371.

Potter, B. J., Mano, M. T., Belling, G. B., McIntosh, G. H., Hua, C., Cragg, B. G., Marshall, J., Wellby, M. L. and Hetzel, B. S. 1982. Retarded fetal brain-development resulting from severe dietary iodine deficiency in sheep. Neuropathology and Applied Neurobiology 8(4): 303-313.

Rainuzzo, J. R., Reitan, K. I. and Olsen, Y. 1997. The significance of lipids at early stages of marine fish: a review. Aquaculture 155(1-4): 103-115.

Ribeiro, A. R. A., Ribeiro, L., Saele, O., Dinis, M. T. and Moren, M. 2012. Iodine and selenium supplementation increased survival and changed thyroid hormone status in Senegalese sole (Solea senegalensis) larvae reared in a recirculation system. Fish Physiology and Biochemistry 38(3): 725-734.

Ribeiro, A. R. A., Ribeiro, L., Saele, O., Hamre, K., Dinis, M. T. and Moren, M. 2011. Iodine-enriched rotifers and Artemia prevent goitre in Senegalese sole (Solea senegalensis) larvae reared in a recirculation system. Aquaculture Nutrition 17(3): 248-257.

Ricker, W. E. 1958. Handbook of computations for biological statistics of fish populations. Bulletin of Fish Resources Board of Canada 119: 1-300.

Robertson, S. M., Friend, M. A. and King, B. J. 2008. Mild congenital goitre increases lamb mortality in southern New South Wales. Australian Journal of Experimental Agriculture 48(6-7): 995-998.

Rodriguez, C., Perez, J. A., Diaz, M., Izquierdo, M. S., FernandezPalacios, H. and Lorenzo, A. 1997. Influence of the EPA/DHA ratio in rotifers on gilthead seabream (Sparus aurata) larval development. Aquaculture 150(1-2): 77-89.

Romaris-Hortas, V., Moreda-Pineiro, A. and Bermejo-Barrera, P. 2009. Microwave assisted extraction of iodine and bromine from edible seaweed for inductively coupled plasma-mass spectrometry determination. Talanta 79(3): 947-952.

Ruz, M., Codoceo, J., Galgani, J., Munoz, L., Gras, N., Muzzo, S., Leiva, L. and Bosco, C. 1999. Single and multiple selenium-zinc-iodine deficiencies affect rat thyroid metabolism and ultrastructure. Journal of Nutrition 129(1): 174-180.

Sæle, Ø. and Pittman, K. A. 2010. Looking closer at the determining of a phenotype? Compare by stages or size, not age. Journal of Applied Ichthyology 26(2): 294-297.

Saele, O., Solbakken, J. S., Watanabe, K., Hamre, K. and Pittman, K. 2003. The effect of diet on ossification and eye migration in Atlantic halibut larvae (Hippoglossus hippoglossus L.). Aquaculture 220(1-4): 683-696.

Sancha, E., van Heezik, Y., Maloney, R., Alley, M. and Seddon, P. 2004. Iodine deficiency affects hatchability of endangered captive kaki (black stilt, Himantopus novaezelandiae). Zoo Biology 23(1): 1-13. 
Schofield, R. M. S., Niedbala, J. C., Nesson, M. H., Tao, Y., Shokes, J. E., Scott, R. A. and Latimer, M. J. 2009. Br-rich tips of calcified crab claws are less hard but more fracture resistant: A comparison of mineralized and heavy-element biological materials. Journal of Structural Biology 166(3): 272-287.

Sherrill, J., Whitaker, B. R. and Wong, G. T. F. 2004. Effects of ozonation on the speciation of dissolved iodine in artificial seawater. Journal of Zoo and Wildlife Medicine 35(3): 347-355.

Solbakken, J. S., Berntssen, M. H. G., Norberg, B., Pittman, K. and Hamre, K. 2002. Different iodine and thyroid hormone levels between Atlantic halibut larvae fed wild zooplankton or Artemia from first exogenous feeding until post metamorphosis. Journal of Fish Biology 61(6): 1345-1362.

Soldin, O. P., O'Mara, D. M. and Aschner, M. 2008. Thyroid hormones and methylmercury toxicity. Biological Trace Element Research 126(1-3): 1-12.

Srivastava, A., Hamre, K., Stoss, J. and Nordgreen, A. 2012. A study on enrichment of the rotifer Brachionus "Cayman" with iodine from different sources. Aquaculture 334-337(0): 82-88.

Sutija, M. and Joss, J. 2005. Thyroid hormone deiodinase revisited: insights from lungfish: a review. Journal of Comparative Physiology B 176: 87-92.

Thompson, A. B. and Harrop, R. T. 1991. Feeding dynamics of fish larvae on copepoda in the western Irish sea, with particular reference to cod Gadus morhua. Marine Ecology-Progress Series 68(3): 213-223.

Tonacchera, M., Pinchera, A., Dimida, A., Ferrarini, E., Agretti, P., Vitti, P., Santini, F., Crump, K. and Gibbs, J. 2004. Relative potencies and additivity of perchlorate, thiocyanate, nitrate, and iodide on the inhibition of radioactive iodide uptake by the human sodium iodide symporter. Thyroid 14(12): 1012-1019.

Vanderpas, J. 2006. Nutritional epidemiology and thyroid hormone metabolism. Annual Review of Nutrition 26: 293-322.

Wan, Y., Jones, P. D., Wiseman, S., Chang, H., Chorney, D., Kannan, K., Zhang, K., Hu, J. Y., Khim, J. S., Tanabe, S., Lam, M. H. and Giesy, J. P. 2010. Contribution of synthetic and naturally occurring organobromine compounds to bromine mass in marine organisms. Environmental Science and Technology 44(16): 6068-6073.

Witt, E. M., Laidley, C. W., Liu, K. K. M., Hirano, T. and Grau, E. G. 2009. Correlation between environmental iodide concentrations and larval growth, survival, and whole body concentrations of thyroid hormones and cortisol in Pacific threadfin (Polydactylus sexfilis). Aquaculture 289(3-4): 357-364.

Wolff, J. and Chaikoff, I. L. 1948. The inhibitory action of iodide upon organic binding of iodine by the normal thyroid gland. Journal of Biological Chemistry 172(2): 855-856.

Xu, J., Yang, X. F., Guo, H. L., Hou, X. H., Liu, L. G. and Sun, X. F. 2006. Selenium supplement alleviated the toxic effects of excessive iodine in mice. Biological Trace Element Research 111(1-3): 229-238. 
661 Yang, X. F., Xu, J., Hou, X. H., Guo, H. L., Hao, L. P., Yao, P., Liu, L. G. and Sun, X. F. 2006. 662 Developmental toxic effects of chronic exposure to high doses of iodine in the mouse. Reproductive Toxicology 22(4): 725-730. 


\section{Table $\mathbf{1}_{\text {(on next page) }}$}

Essential element concentrations in control and sodium iodide (HI+) enriched rotifers. 


\begin{tabular}{lllll} 
Mineral & units & Control rotifers & HI+rotifers & P value \\
\hline Iodine & $\mathrm{mg} \mathrm{kg}^{-1} \mathrm{DW}$ & $0.60 \pm 0.33^{\mathrm{a}}$ & $129 \pm 101^{\mathrm{b}}$ & $0.04^{*}$ \\
Manganese & & $9.0 \pm 0.6^{\mathrm{a}}$ & $8.0 \pm 0.4^{\mathrm{b}}$ & $0.03^{*}$ \\
Copper & mean $\pm \mathrm{SD}$ & $10.8 \pm 6.6$ & $12.1 \pm 6.2$ & 0.78 \\
Zinc & $\mathrm{n}=4$ & $41 \pm 2$ & $38 \pm 4$ & 0.24 \\
Iron & & $150 \pm 10^{\mathrm{a}}$ & $135 \pm 3^{\mathrm{b}}$ & $0.04^{*}$ \\
Cobalt & & $0.17 \pm 0.07$ & $0.16 \pm 0.06$ & 0.85 \\
Selenium & & $0.03 \pm 0.01$ & $0.04 \pm 0.02$ & 0.76 \\
\hline Calcium & $\mathrm{g} \mathrm{kg}^{-1} \mathrm{DW}$ & $2.2 \pm 0.2$ & $2.6 \pm 0.3$ & 0.16 \\
Phosphorus & & $12.3 \pm 0.6$ & $11.1 \pm 0.8$ & 0.13 \\
Magnesium & $\mathrm{mean} \pm \mathrm{SD}$ & $5.5 \pm 0.8$ & $7.0 \pm 0.9$ & 0.09 \\
Potassium & $\mathrm{n}=3$ & $12.0 \pm 0.2$ & $11.7 \pm 0.3$ & 0.31 \\
\hline
\end{tabular}

$1 *$ Letters denote statistically significant differences between rotifer groups (one-way ANOVA p $<0.05$ ).

2 


\section{Table $2_{\text {(on next page) }}$}

The weight, length, condition factor and percent of skeletal deformities in $124 \mathrm{dph}$ cod fed control, MI or HI rotifers from 5 to $39 \mathrm{dph}$ and identical diets thereafter. 


\begin{tabular}{|c|c|c|c|c|c|}
\hline & & Control & MI & HI & P value \\
\hline \multirow[t]{3}{*}{ Growth } & Weight (g) & $2.49 \pm 0.22$ & $2.56 \pm 0.18$ & $2.44 \pm 0.25$ & 0.67 \\
\hline & Length (cm) & $6.12 \pm 0.17$ & $6.19 \pm 0.19$ & $6.09 \pm 0.18$ & 0.75 \\
\hline & Condition factor & $1.06 \pm 0.05$ & $1.05 \pm 0.01$ & $1.04 \pm 0.01$ & 0.43 \\
\hline \multirow{10}{*}{$\begin{array}{l}\text { Skeletal } \\
\text { deformities }^{\mathrm{a} *}\end{array}$} & Lower jaw & $4.0 \pm 2.0$ & $9.3 \pm 7.6$ & $5.3 \pm 4.7$ & 0.96 \\
\hline & Short upper jaw & $3.3 \pm 3.1$ & 0 & 0 & 0.26 \\
\hline & Palate bone & $1.3 \pm 1.2$ & 0 & $3.0 \pm 4.2$ & 0.28 \\
\hline & Neck axis average (degrees) ${ }^{\mathrm{b}}$ & $186 \pm 0.4$ & $186 \pm 0.6$ & $184 \pm 1.0$ & 0.01 \\
\hline & Neck axis $<183$ degrees & $25 \pm 2$ & $23 \pm 10$ & $39 \pm 12$ & 0.08 \\
\hline & Fused vertebrate & $26 \pm 6$ & $15 \pm 5$ & $29 \pm 10$ & 0.45 \\
\hline & $\begin{array}{l}\text { No. of affected vertebrae (average } \\
\text { fish }^{-1} \text { ) }\end{array}$ & $2.1 \pm 0.2$ & $2.6 \pm 0.6$ & $2.6 \pm 0.6$ & 0.39 \\
\hline & Scoliosis & $17 \pm 2$ & $21 \pm 7$ & $15 \pm 4$ & 0.42 \\
\hline & Back axis & $1.3 \pm 1.2$ & $1.3 \pm 1.2$ & $3.1 \pm 1.3$ & 0.10 \\
\hline & Total fish with malformation & $58 \pm 5$ & $52 \pm 7$ & $64 \pm 11$ & 0.26 \\
\hline
\end{tabular}

Data are mean $\pm S D(n=3)$ except for HI data which are $n=2$.

a $\%$ of population unless otherwise indicated

${ }^{\mathrm{b}}$ Normal neck angle is $180 \pm 3^{\circ}$ (Baeverfjord et al., undated)

* Data analysed using regression $(p<0.05)$ 


\section{Figure 1}

Cod larvae length and dry weight

L ength (Data set $\mathbf{L}$; $\mathrm{mm} \mathrm{fish}^{-1}$, left y axis) and dry weight (Data set $\mathbf{W}$; $\mathrm{mg}_{\text {fish }}{ }^{-1}$, right y axis) of cod larvae fed control $(\square)$, MI ( $\circ$ ) or HI ( • ) rotifers, from 5 to $30 \mathrm{dph}$. At 5 dph, data are mean \pm SD of 2 analytical parallels for dry weight and mean \pm SD $(n=30)$ for length. Data at all other dph are mean \pm SD ( $n=3$ ) where $n$ represents the average of 10 larvae tank $^{-1}$ measured for length, and a group of 47 to 520 larvae group weighed then counted to determine individual mass.

\section{Length and weight}

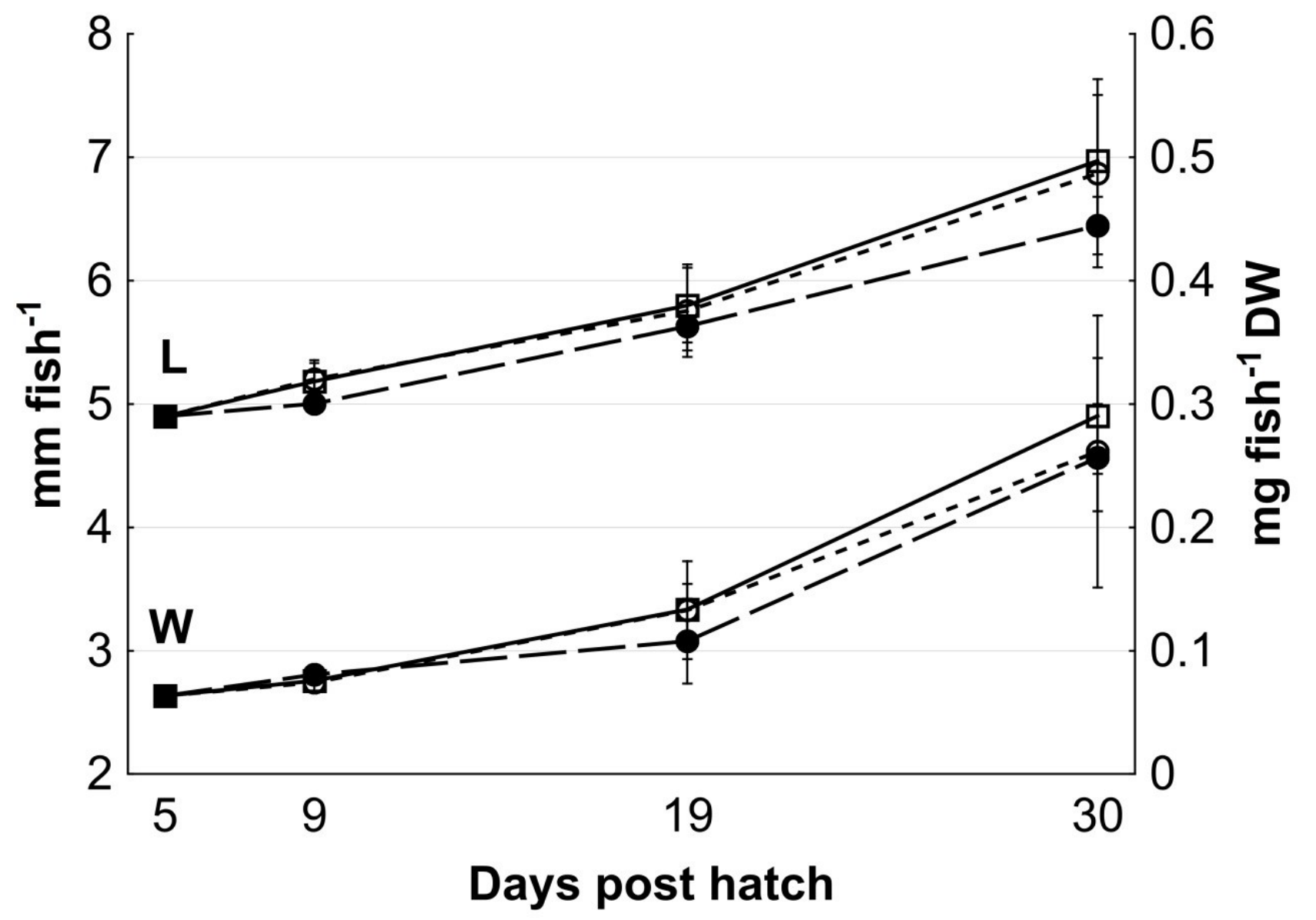




\section{Figure 2}

Essential micro element concentration in whole cod larvae

Essential micro element concentrations ( $\mathrm{mg} \mathrm{kg}^{-1} \mathrm{DW}$ ) in whole cod larvae fed either control ( $\square$ ), MI $(\circ)$ or $\mathrm{HI}(\bullet$ ) rotifers, from 5 to $30 \mathrm{dph}$. Letters denote statistically significant differences in mineral concentrations between treatments at a given day (one-way ANOVA; $\mathrm{p}<0.05$ ). Data are mean \pm SD $(n=3)$, except at 5 dph where data are mean \pm SD of analytical parallels.
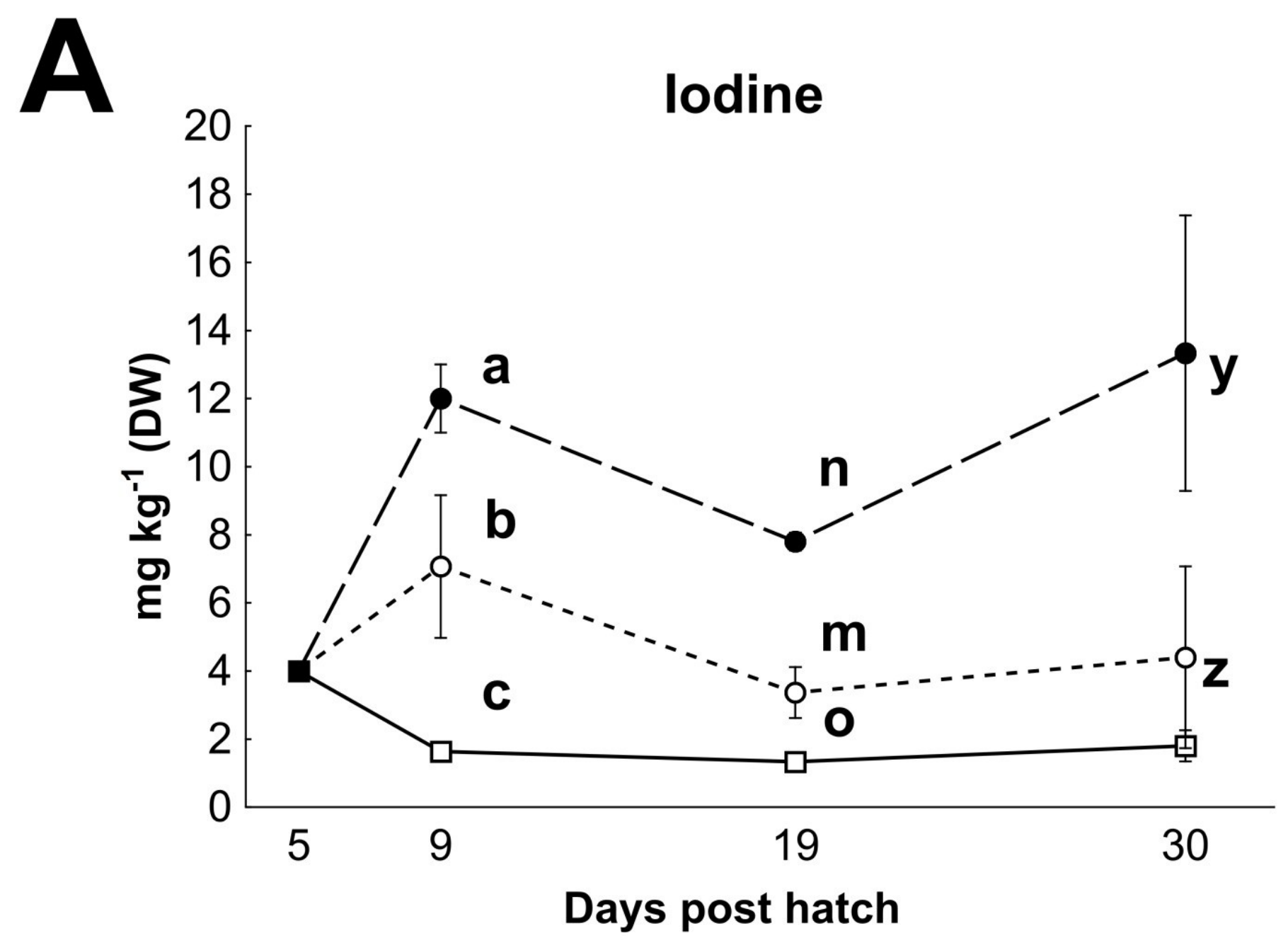
Figure 3

Essential micro element concentration in whole cod larvae

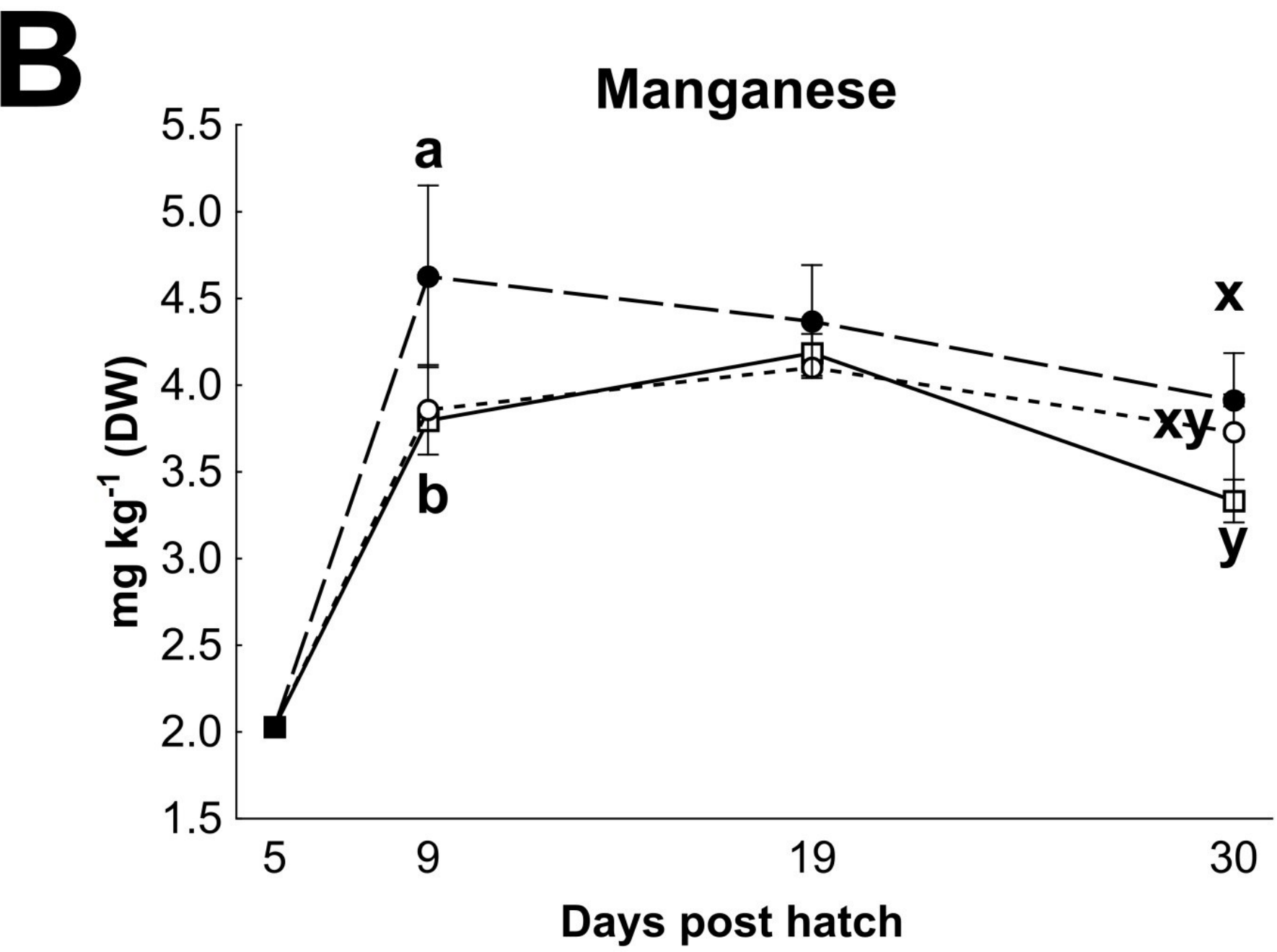




\section{Figure 4}

Essential micro element concentration in whole cod larvae
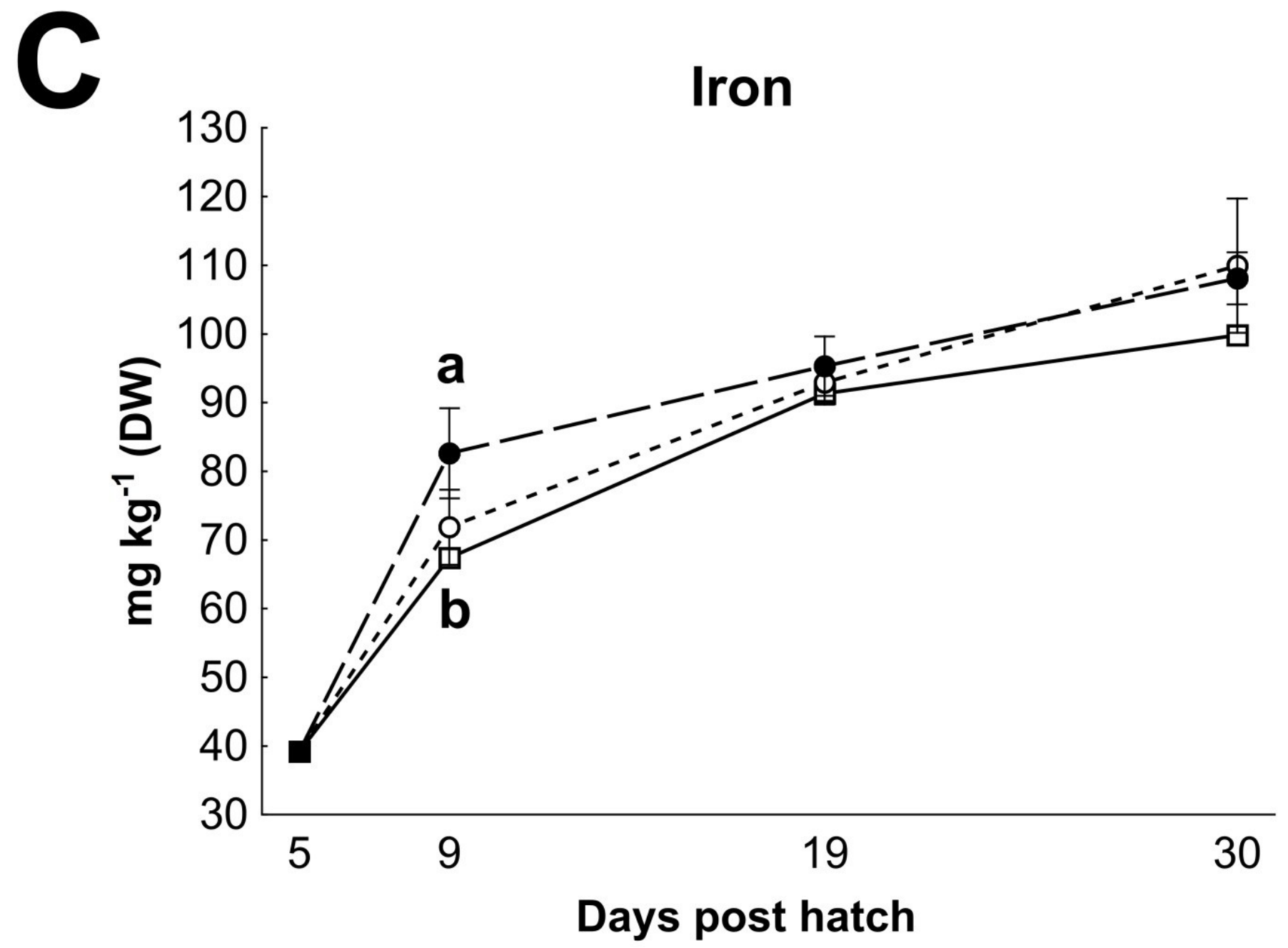


\section{Figure 5}

Essential micro element concentration in whole cod larvae

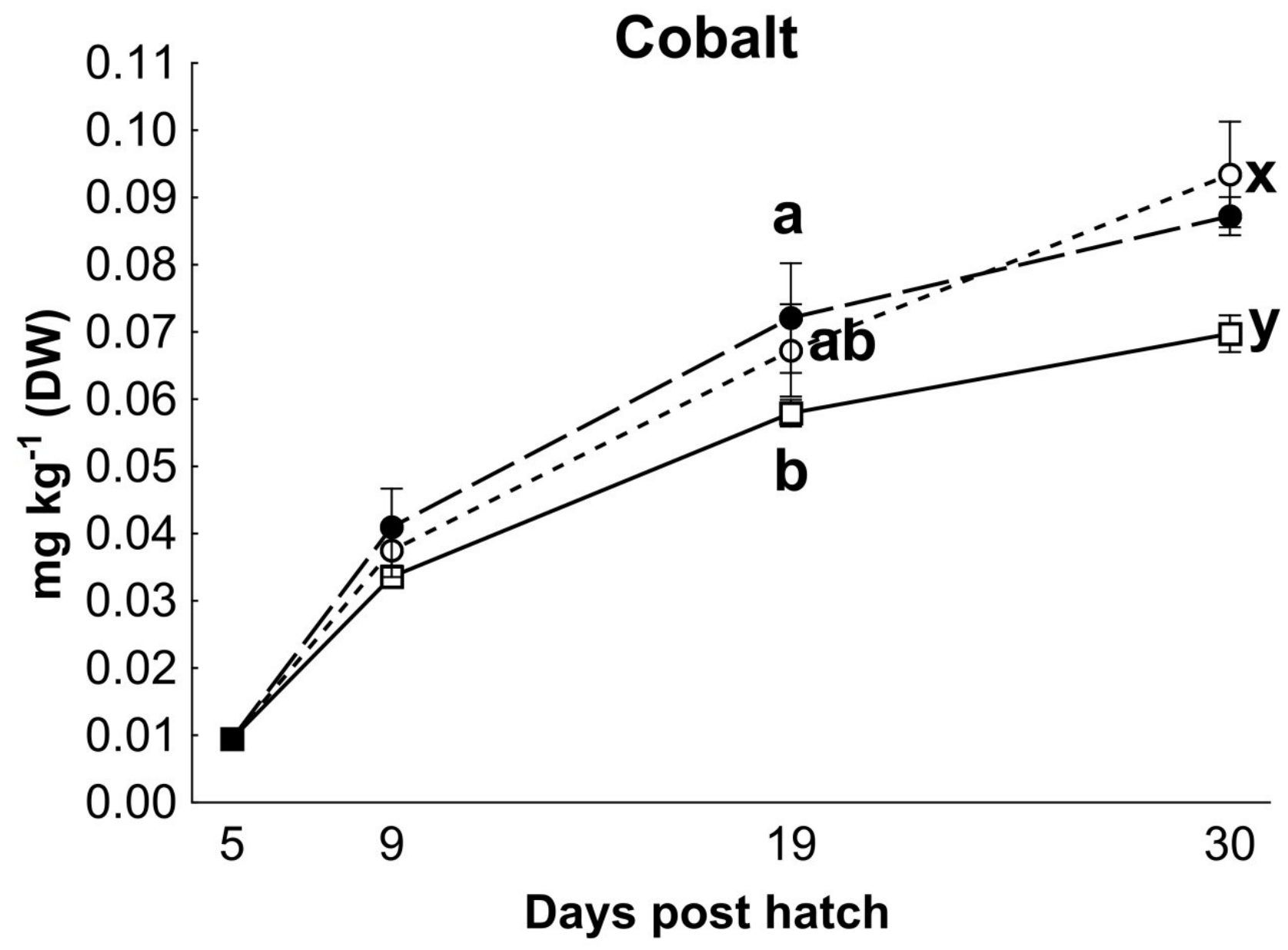




\section{Figure 6}

Essential micro element concentration in whole cod larvae
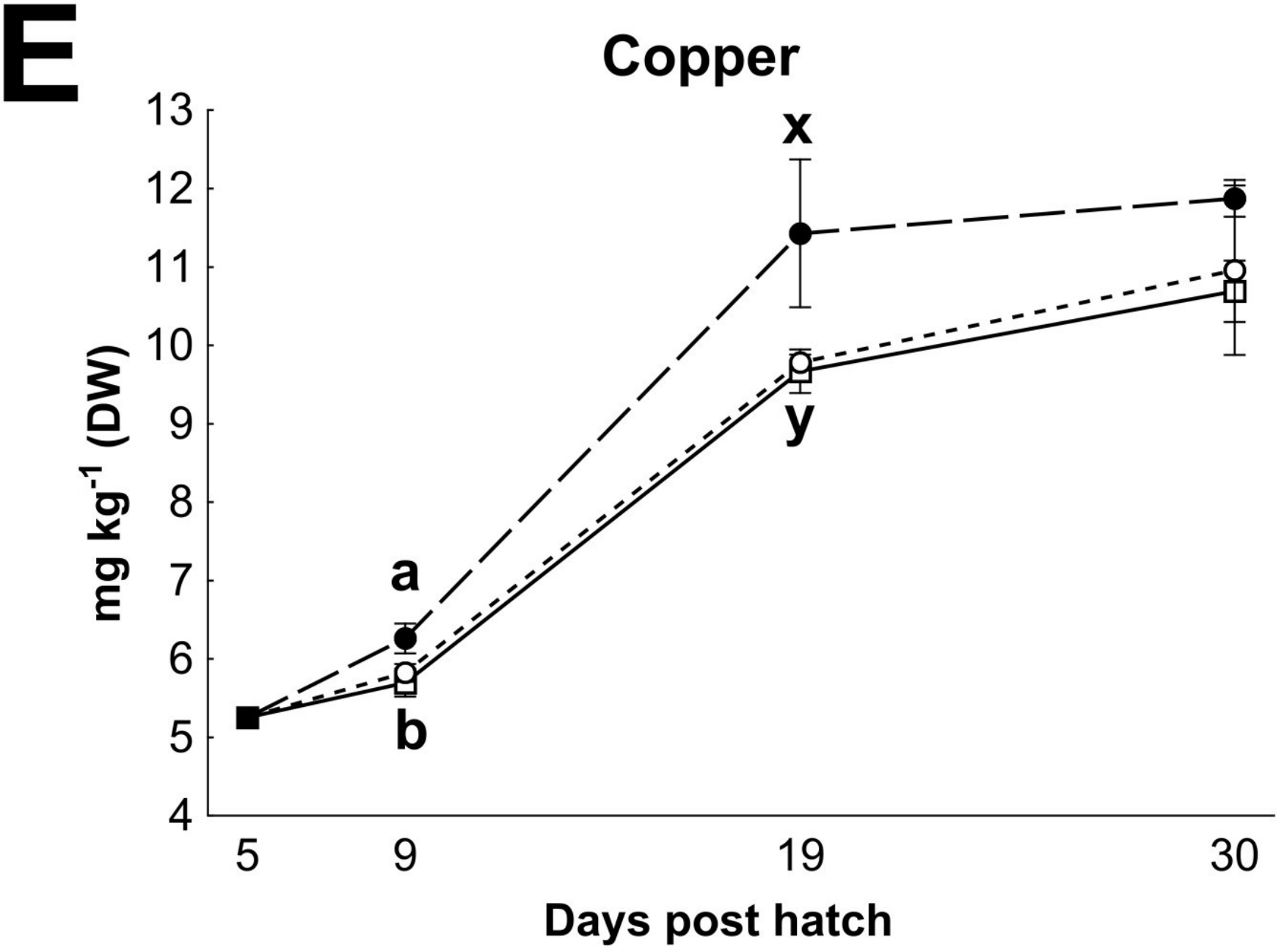


\section{Figure 7}

Essential micro element concentration in whole cod larvae
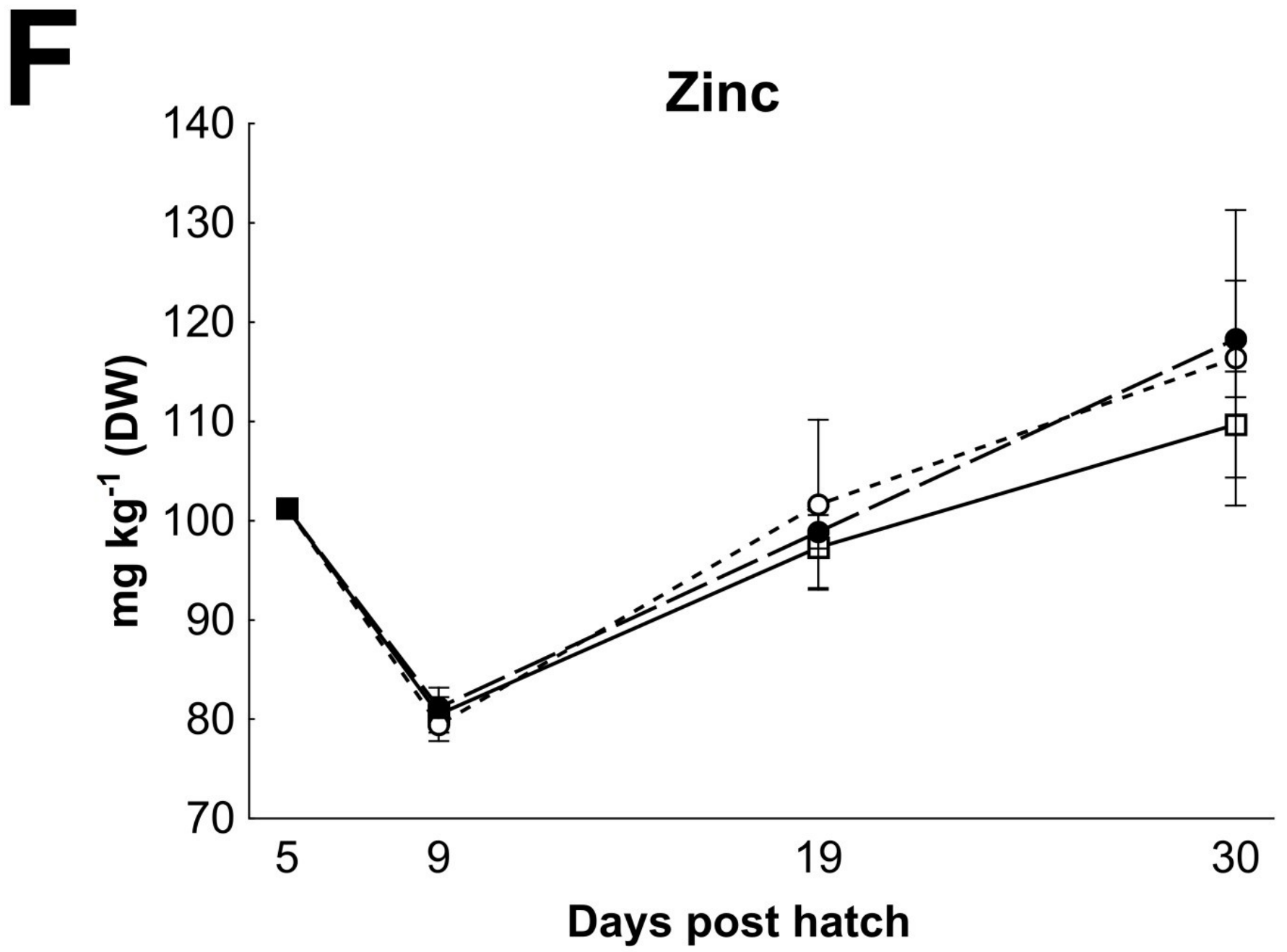


\section{Figure 8}

Essential micro element concentration in whole cod larvae

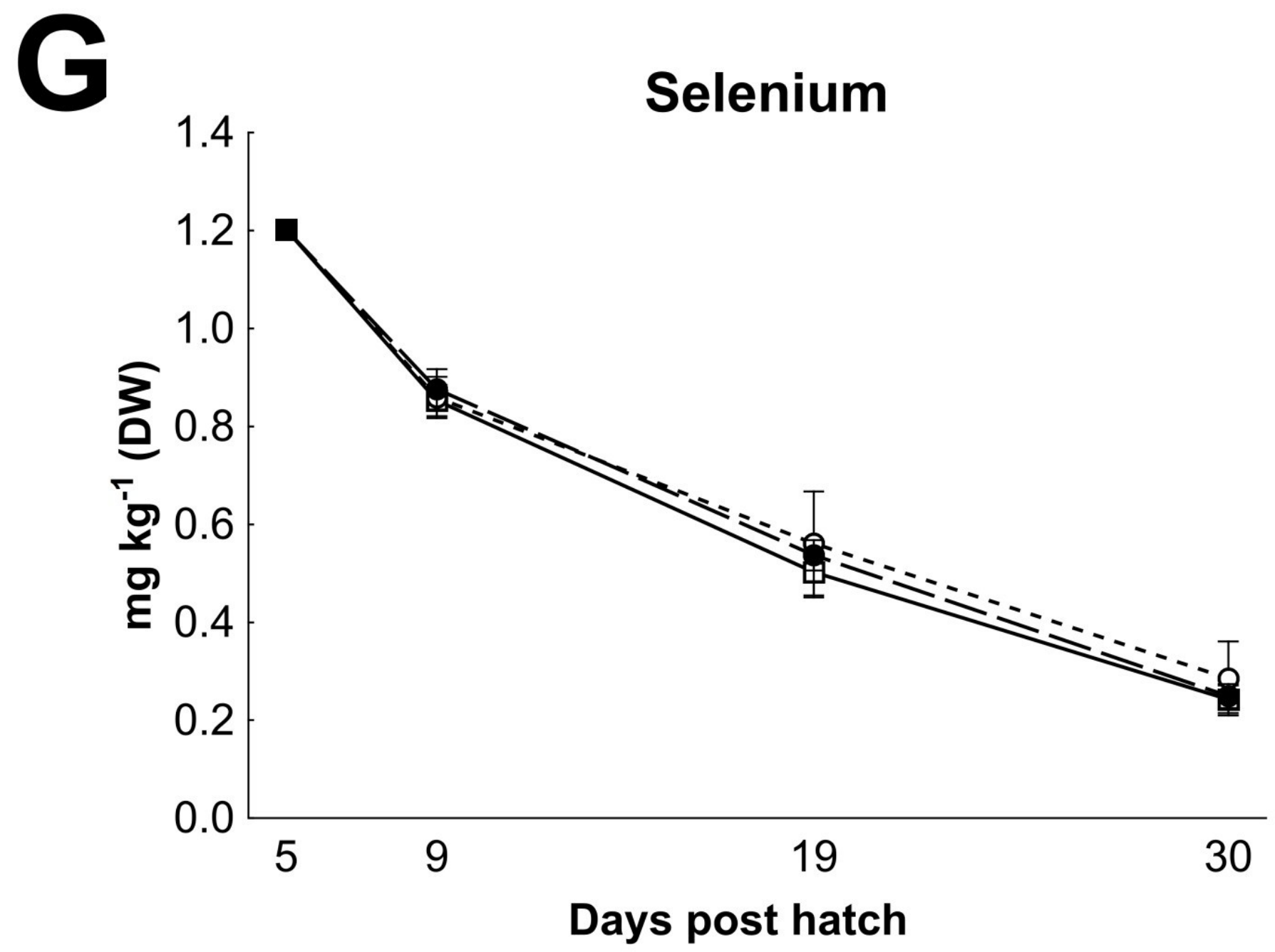




\section{Figure 9}

Essential macro element concentrations in whole cod larvae

Essential macro mineral concentrations ( $\mathrm{g} \mathrm{kg}^{-1} \mathrm{DW}$ ) in whole cod larvae fed either control ( $\square$ ), MI $(\circ)$ or $\mathrm{HI}(\bullet$ ) rotifers, from 5 to $30 \mathrm{dph}$. Letters denote statistically significant differences in mineral concentrations between treatments at a given day (one-way ANOVA, $\mathrm{p}<0.05$ ). Data are mean \pm SD $(n=3)$, except at 5 dph where data are from a single analysis.
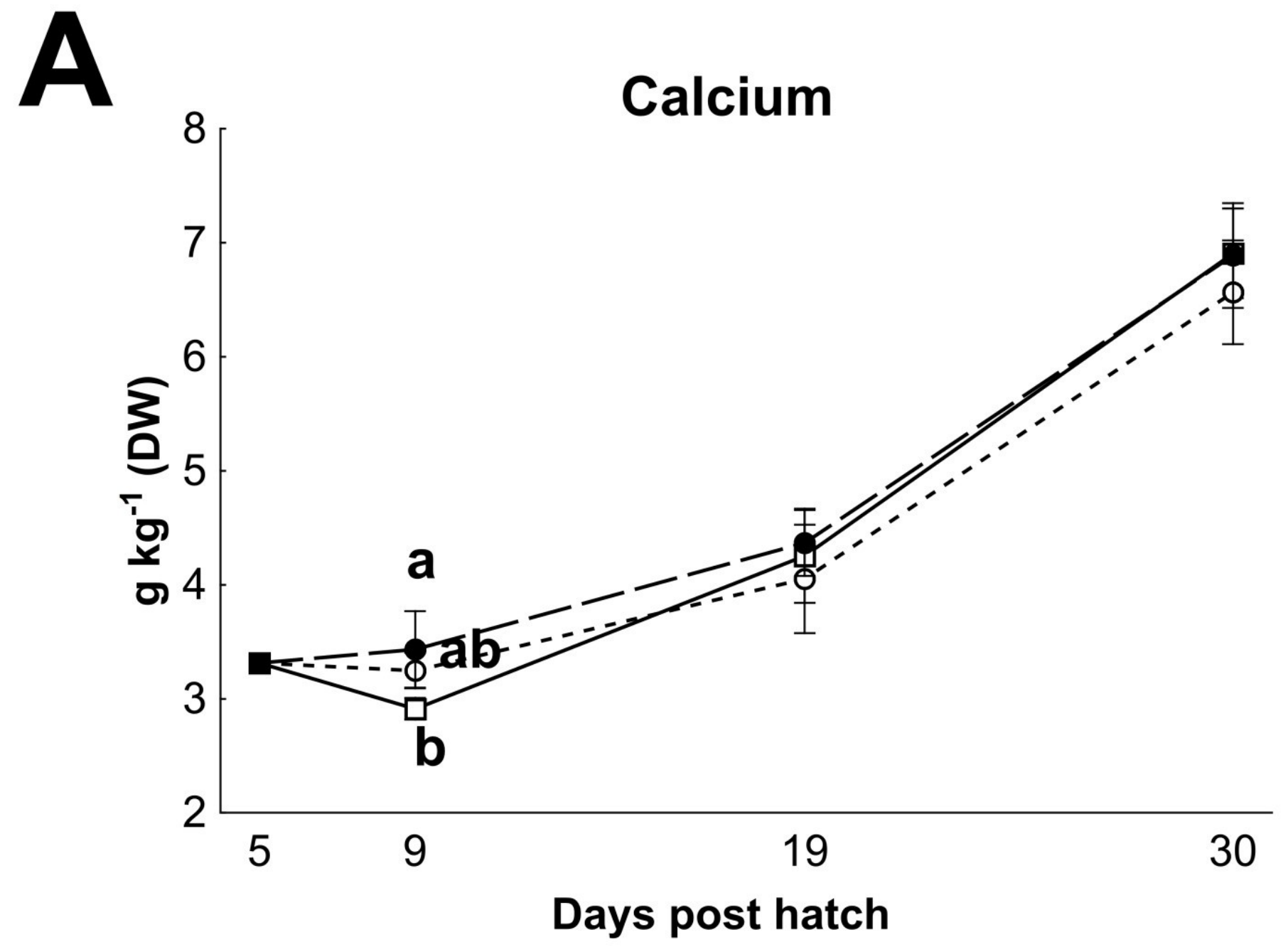
Figure 10

Essential macro element concentrations in whole cod larvae
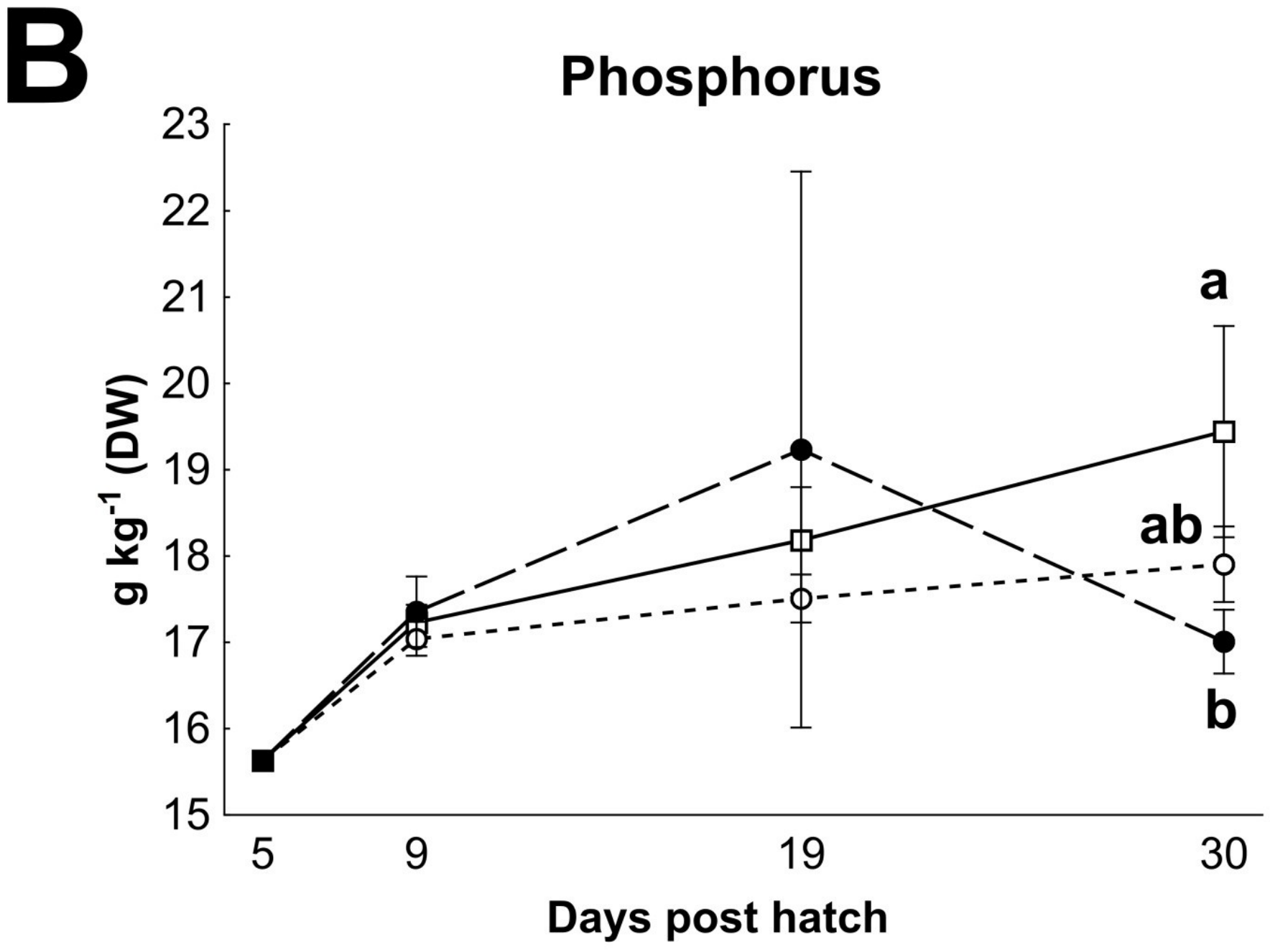


\section{Figure 11}

Essential macro element concentrations in whole cod larvae
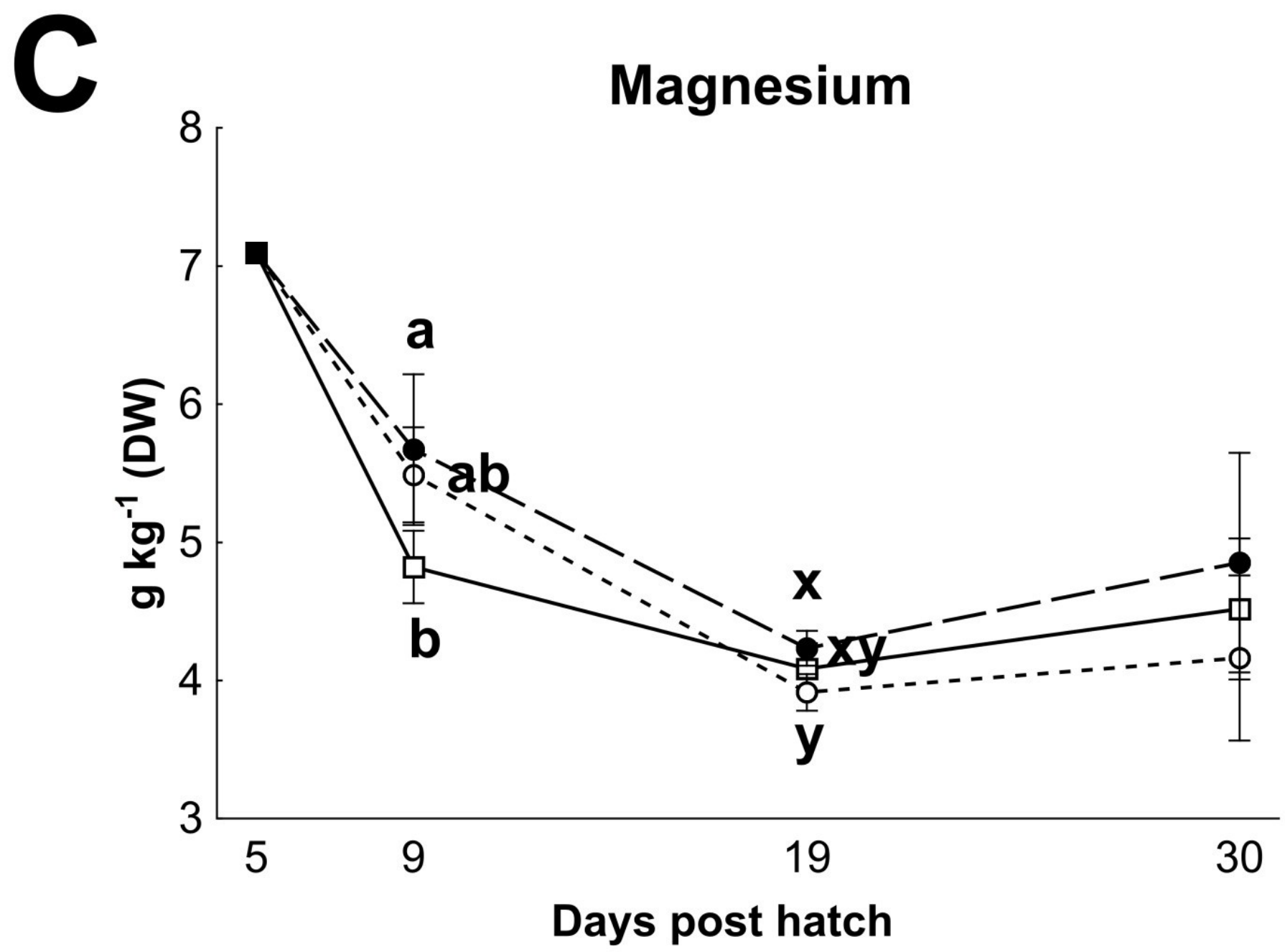
Figure 12

Essential macro element concentrations in whole cod larvae
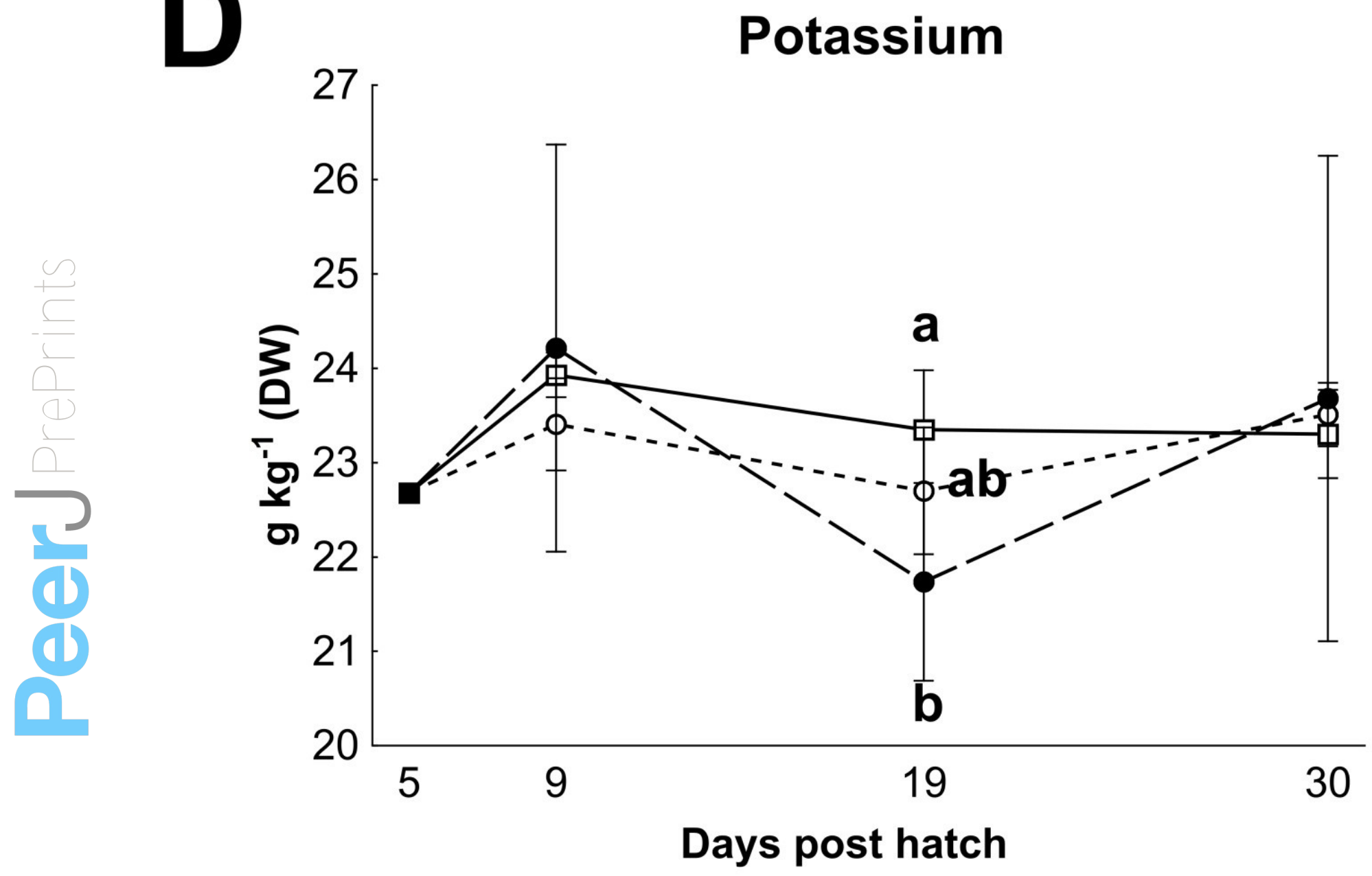


\section{Figure 13}

Cod larvae iodine concentration in relation to their feed

Ratio of iodine concentration (mg kg ${ }^{-1} \mathrm{DW}$ ) in cod larvae versus their diet (rotifers iodine levels (mg $\left.\mathrm{kg}^{-1} \mathrm{DW}\right)$ ). $\mathrm{X}$ axis is $\log$ transformed. Line represents best fit model (Morrison Ki, $\mathrm{R}^{2}=0.94$ ). Data are mean $\pm \mathrm{SD}(\mathrm{n}=9)$.

\section{lodine ratio}

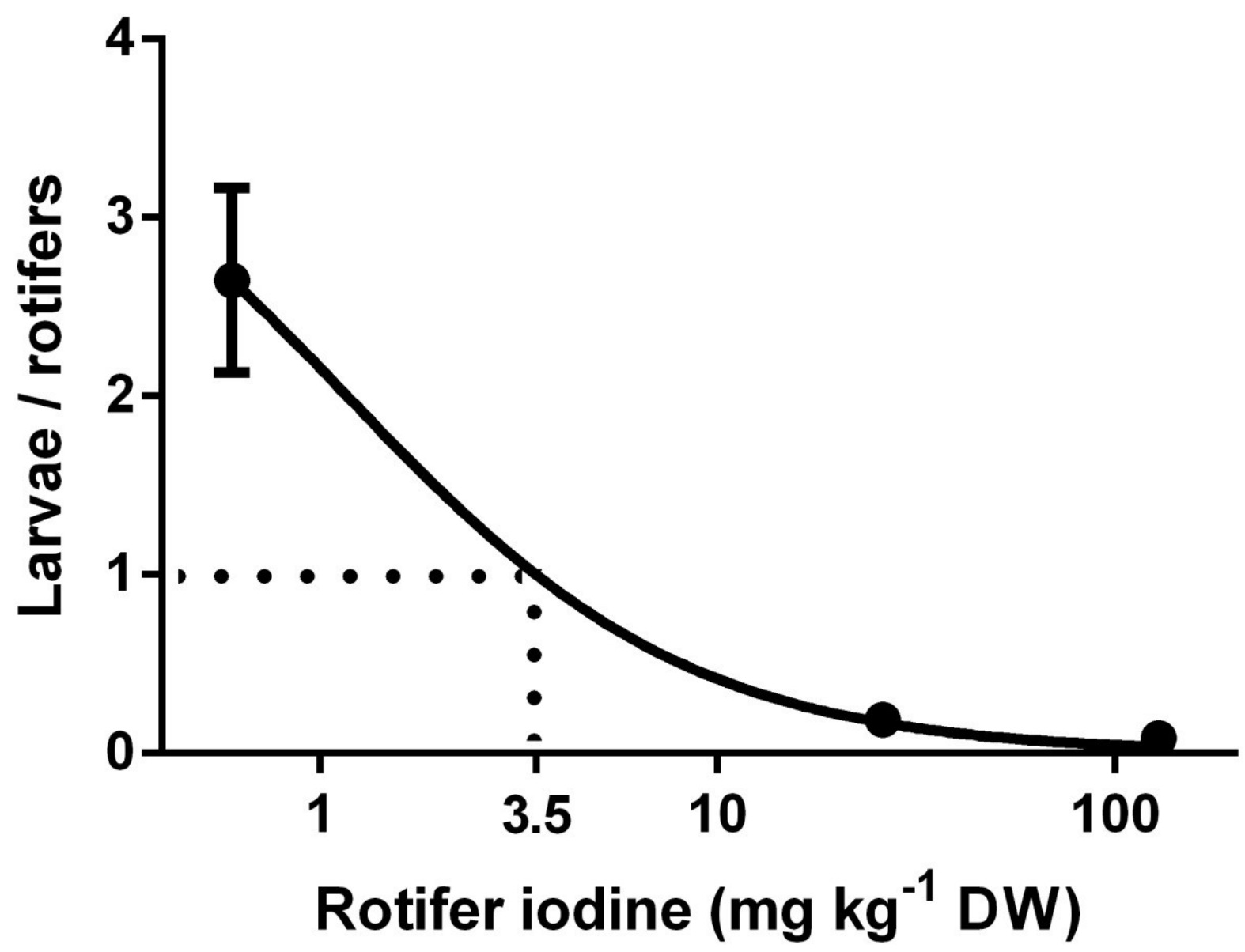




\section{Figure 14}

Cod larvae thyroid hormone levels and ratios

Normalised mean thyroid hormone levels (NML) in cod larvae fed either control ( $\square$ ), MI ( $~ \circ$ ) or HI $(\bullet)$ rotifers. Graph A is tri-iodothyronine $\left(\mathrm{T}_{3}\right)$, Graph B is thyroxine $\left(\mathrm{T}_{4}\right)$, while graph $\mathrm{C}$ is the ratio between the NML of $\mathrm{T}_{3} / \mathrm{T}_{4}$. Data are mean $\pm \mathrm{SD}(\mathrm{n}=3)$ for all data points except controls at $30 \mathrm{dph}$ which has an outlier removed in graph $B$ and $C(n=2)$.

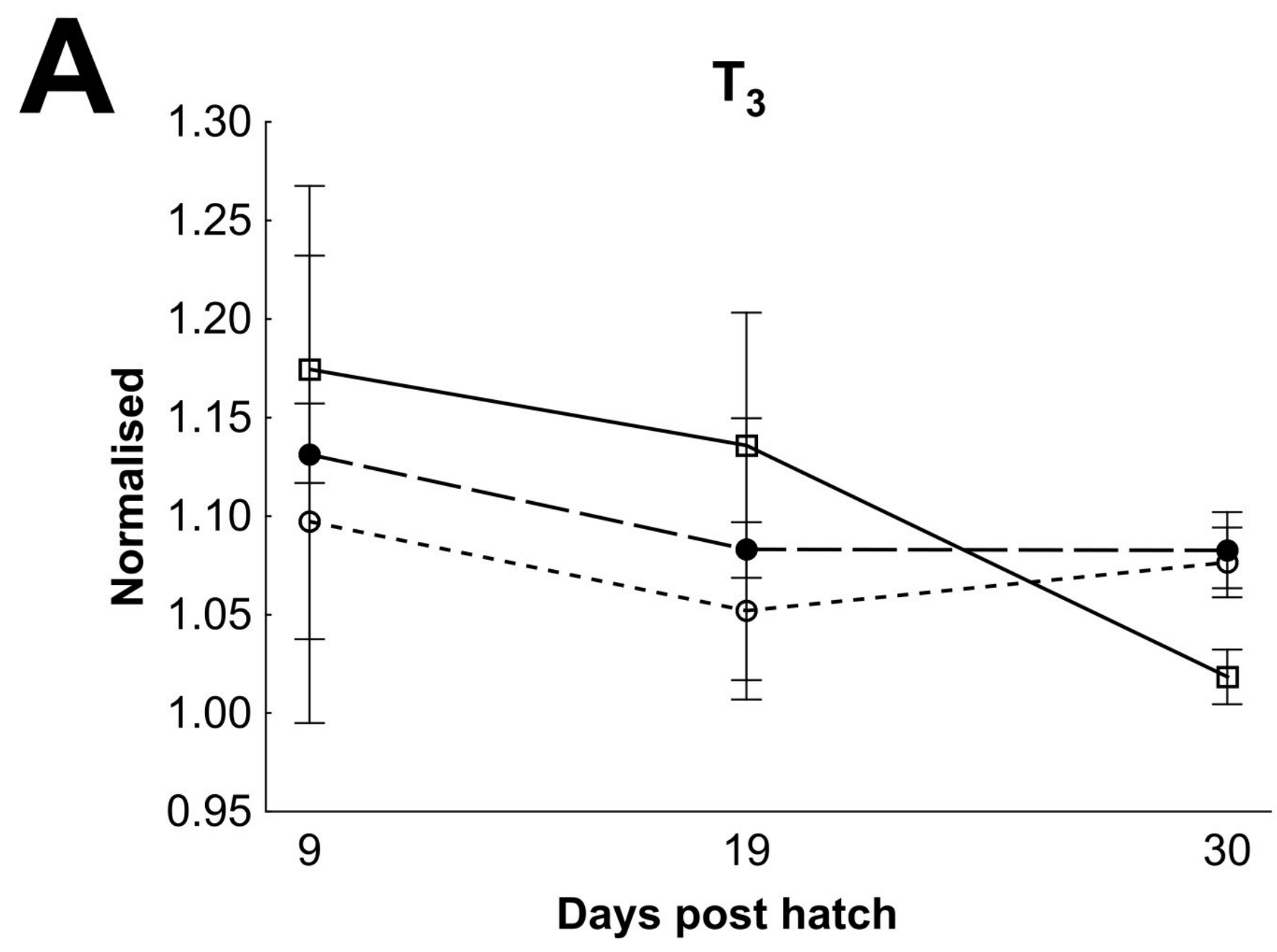


Figure 15

Cod larvae thyroid hormone levels and ratios

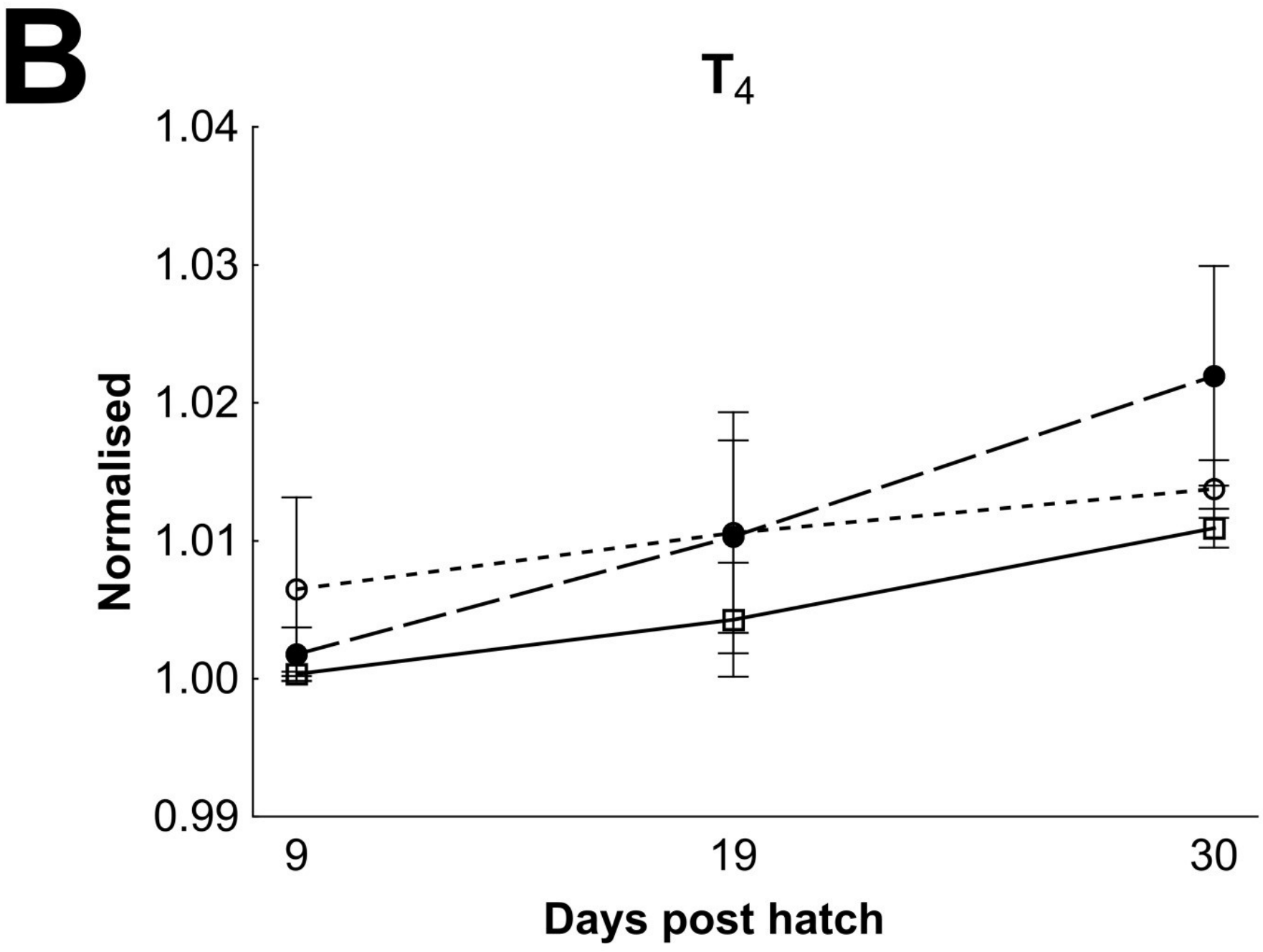


Figure 16

Cod larvae thyroid hormone levels and ratios

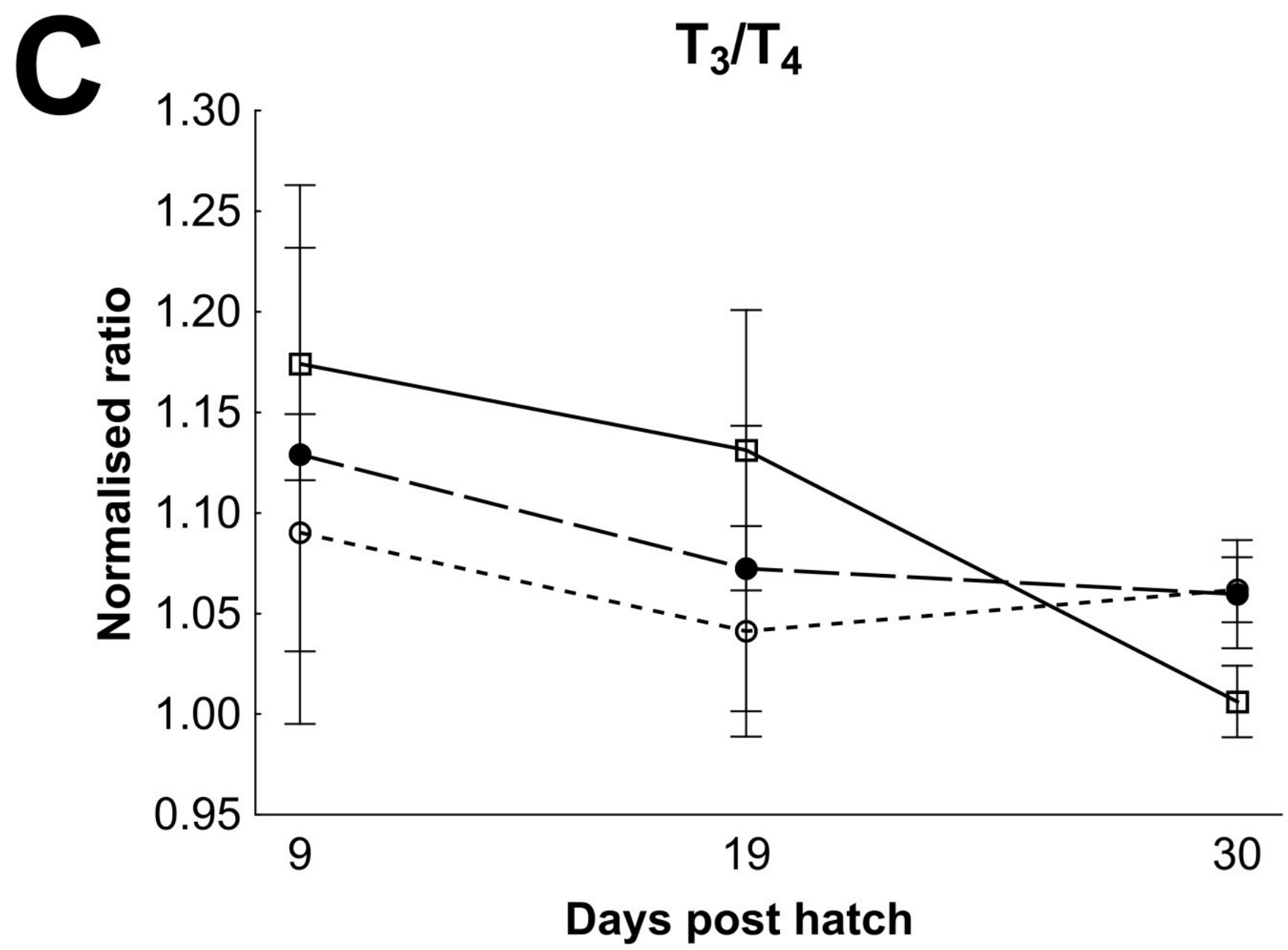




\section{Figure 17}

Cod larvae thyroid follicle morphology

Thyroid follicle morphology in cod larvae fed either control ( $\square$ ), MI ( ० ) or HI ( • ) rotifers. Graph A shows the total number of follicles per fish, Graph B is the total thyroid follicle volume per fish, Graphs C and D show the volume of colloid or epithelium per fish, Graph E shows the ratio between the colloid and epithelium volumes. Letters denote statistically significant differences between treatments per time point (one-way ANOVA, $\mathrm{p}<0.05$ ). Data are mean \pm SD $(n=3)$ where $n$ consists of the average measurements from two fish per tank at 19 and $30 \mathrm{dph}$, and one fish per tank at $37 \mathrm{dph}$.
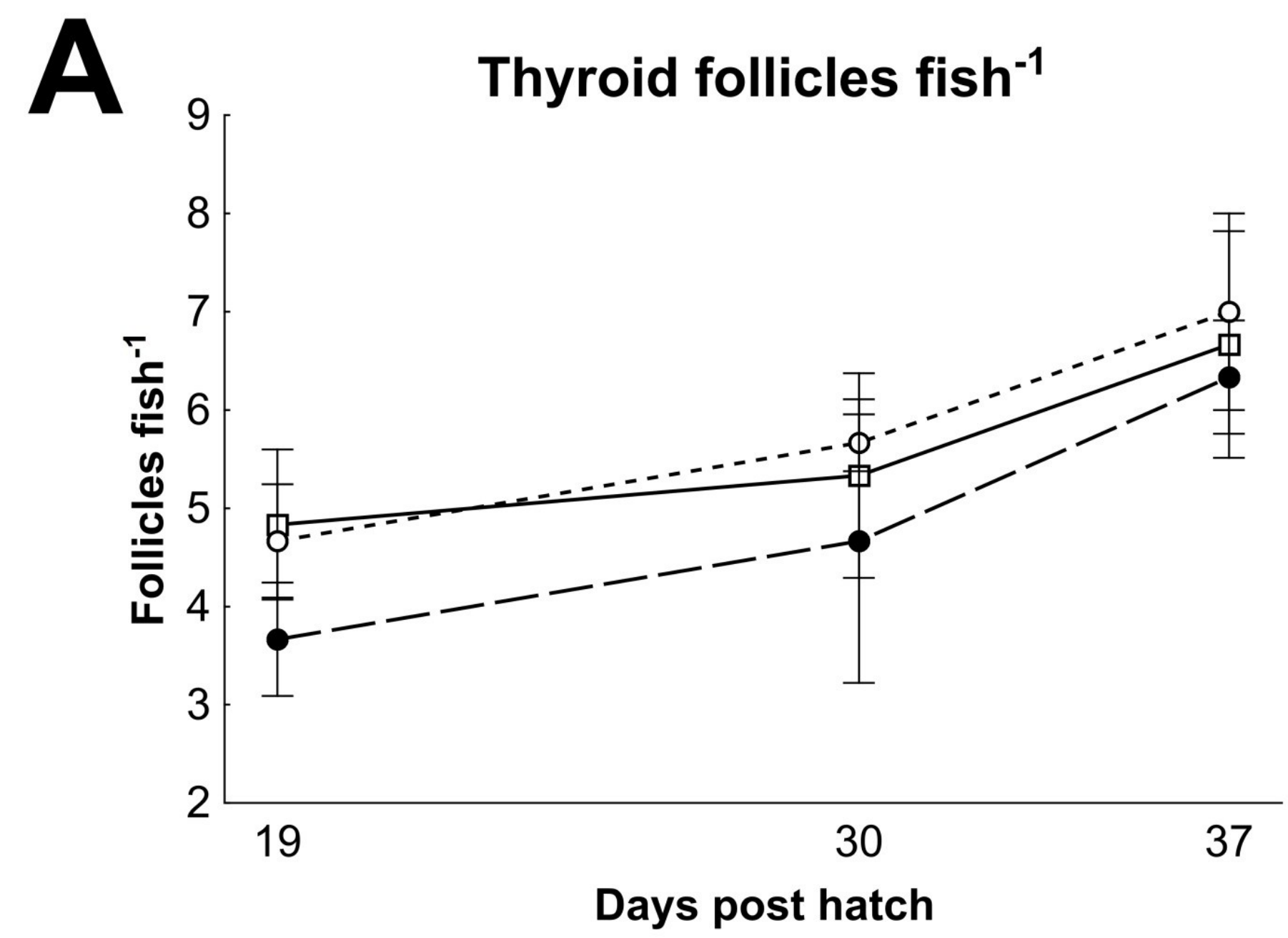
Figure 18

Cod larvae thyroid follicle morphology

\section{Total thyroid follicle volume}

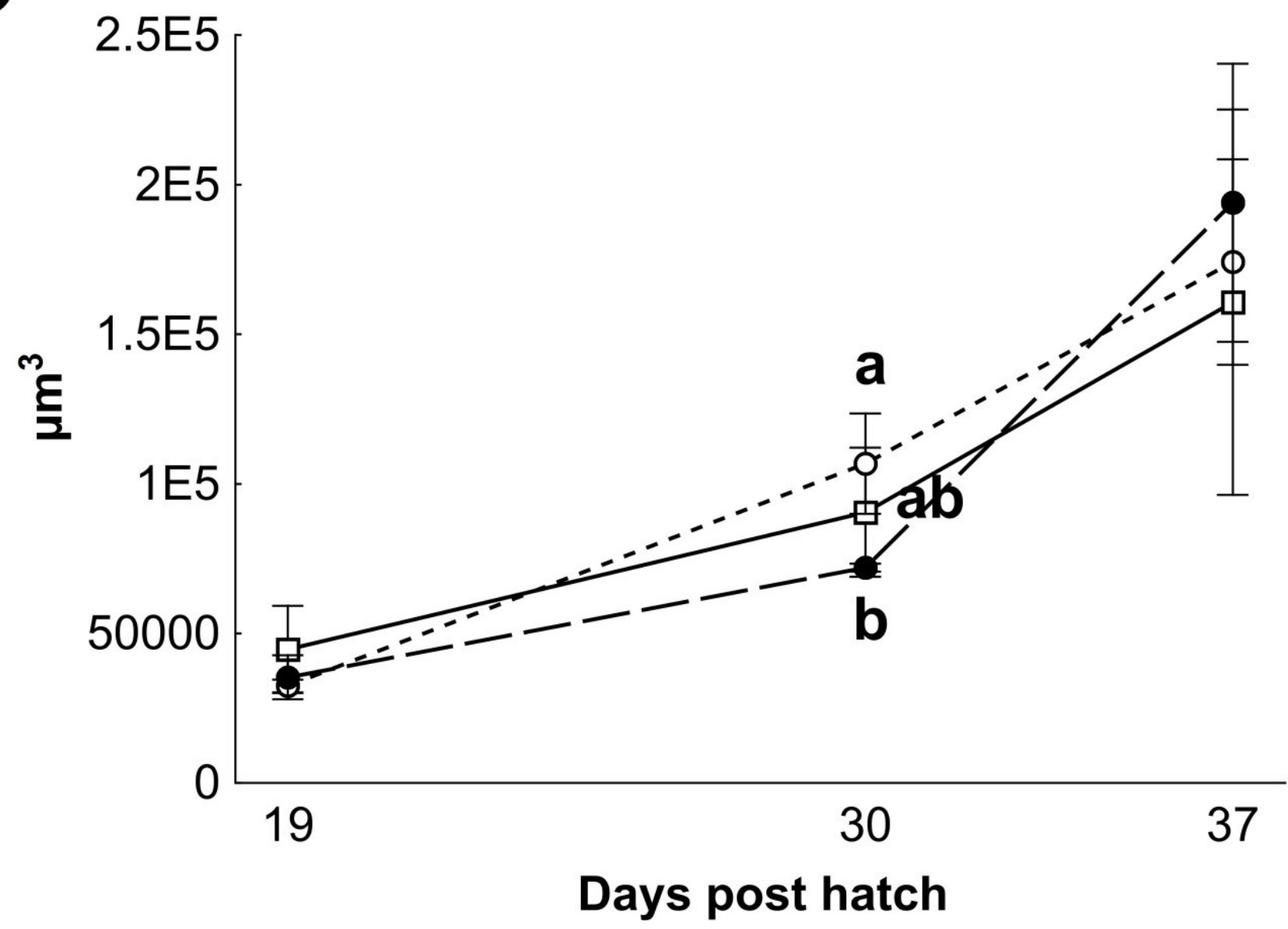


Figure 19

Cod larvae thyroid follicle morphology

Colloid volume

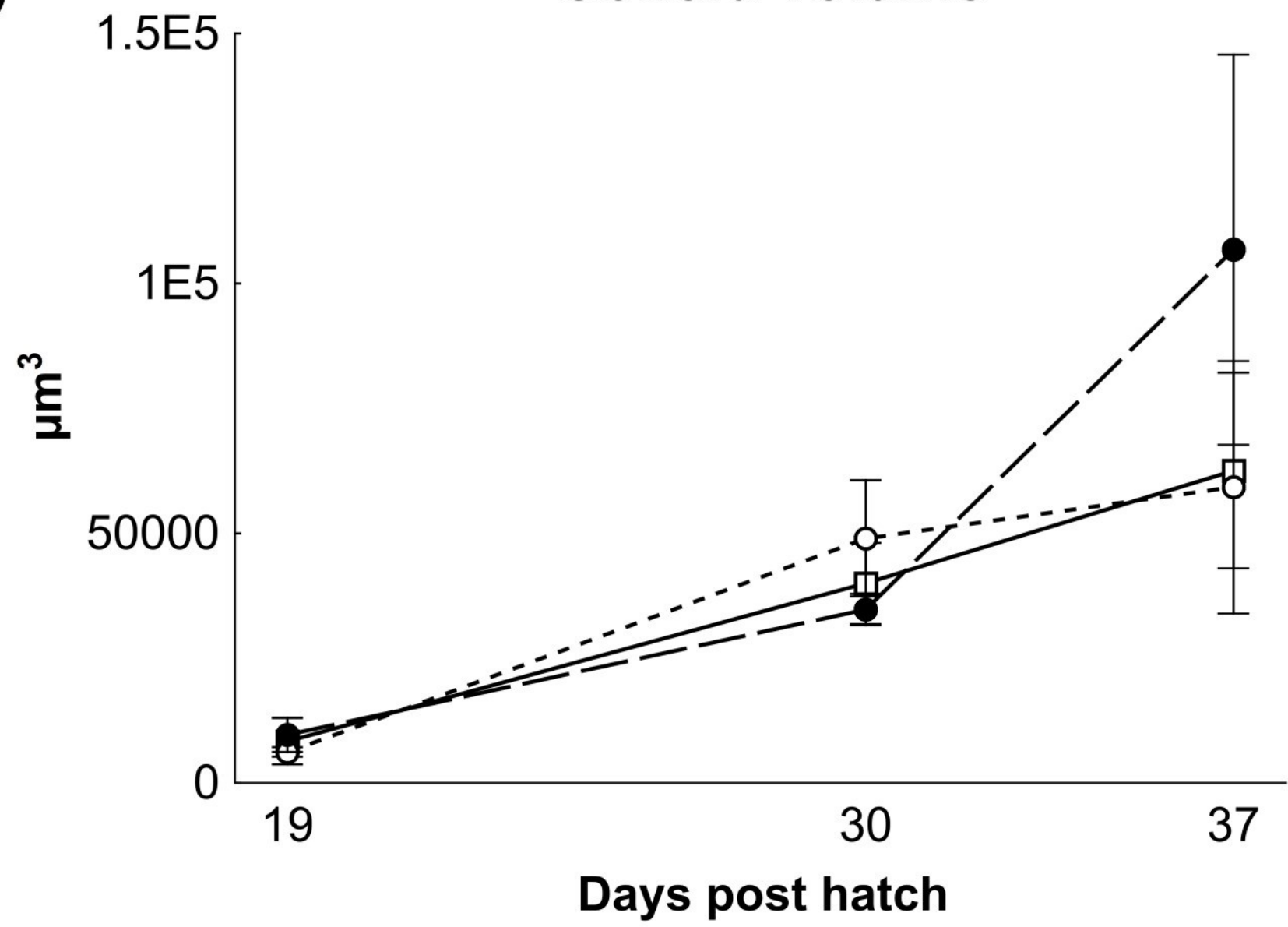


Figure 20

Cod larvae thyroid follicle morphology

\section{Epithelium volume}

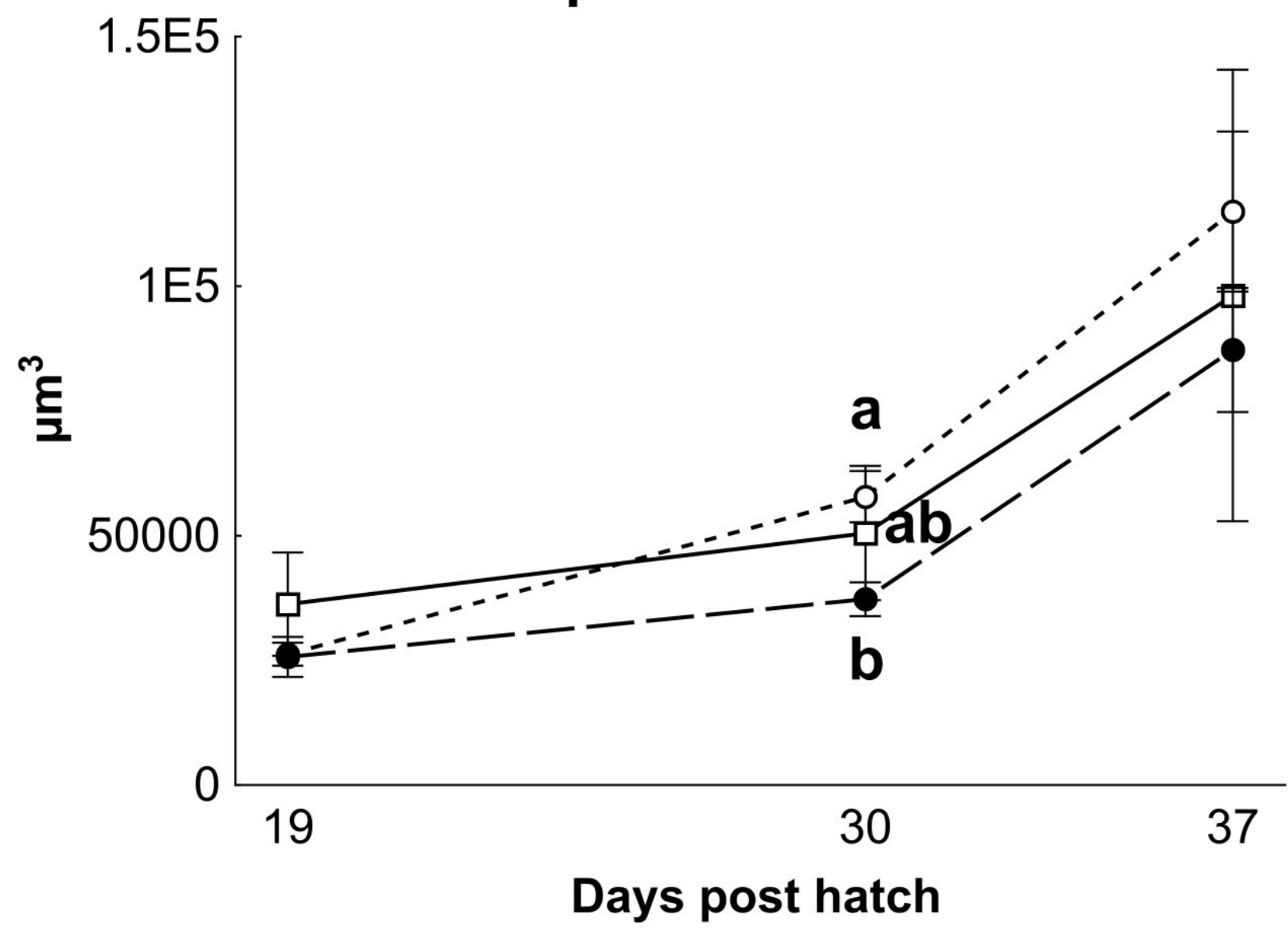


Figure 21

Cod larvae thyroid follicle morphology

\section{Colloid/Epithelium}

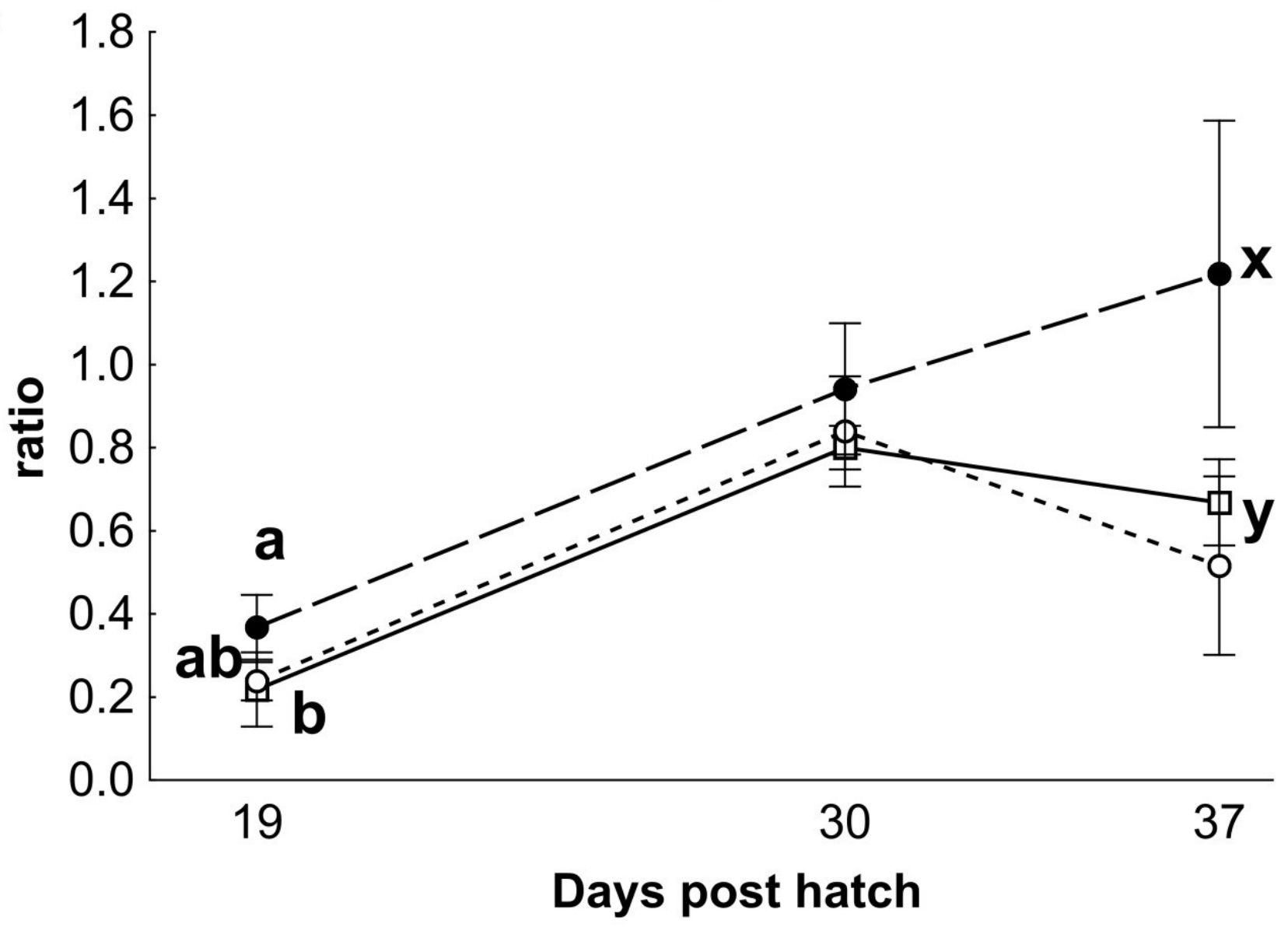




\section{Figure 22}

Thyroid follicle sections from cod larvae

Thyroid follicle section from c od larvae (37 dph) fed either control (A) or HI ( B ) rotifers. Sections are stained with toulidine blue. C; thyroid follicle colloid, E; example of thyroid follicle epithelium. Scale bars are $100 \mu \mathrm{m}$.

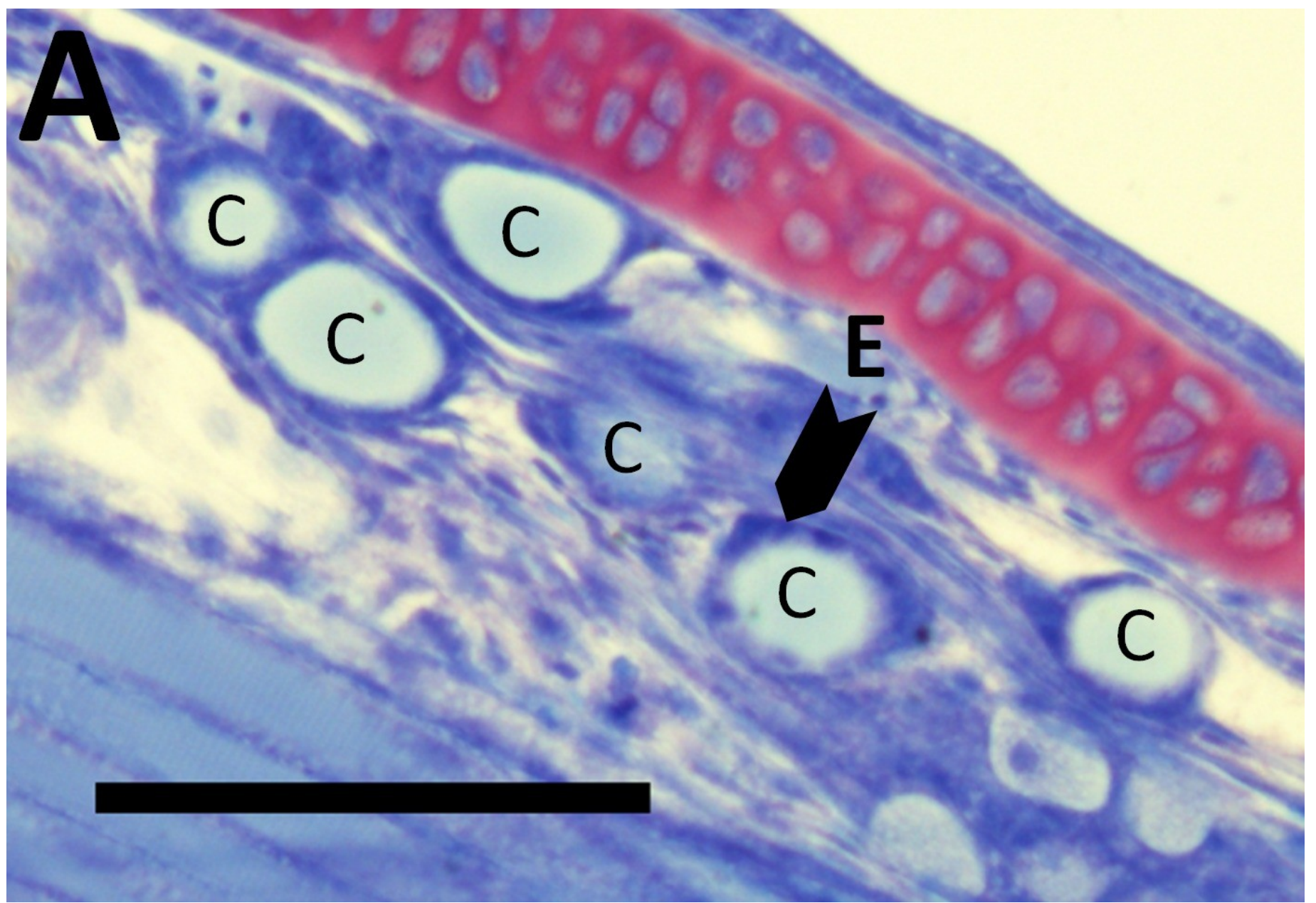




\section{Figure 23}

Thyroid follicle sections from cod larvae

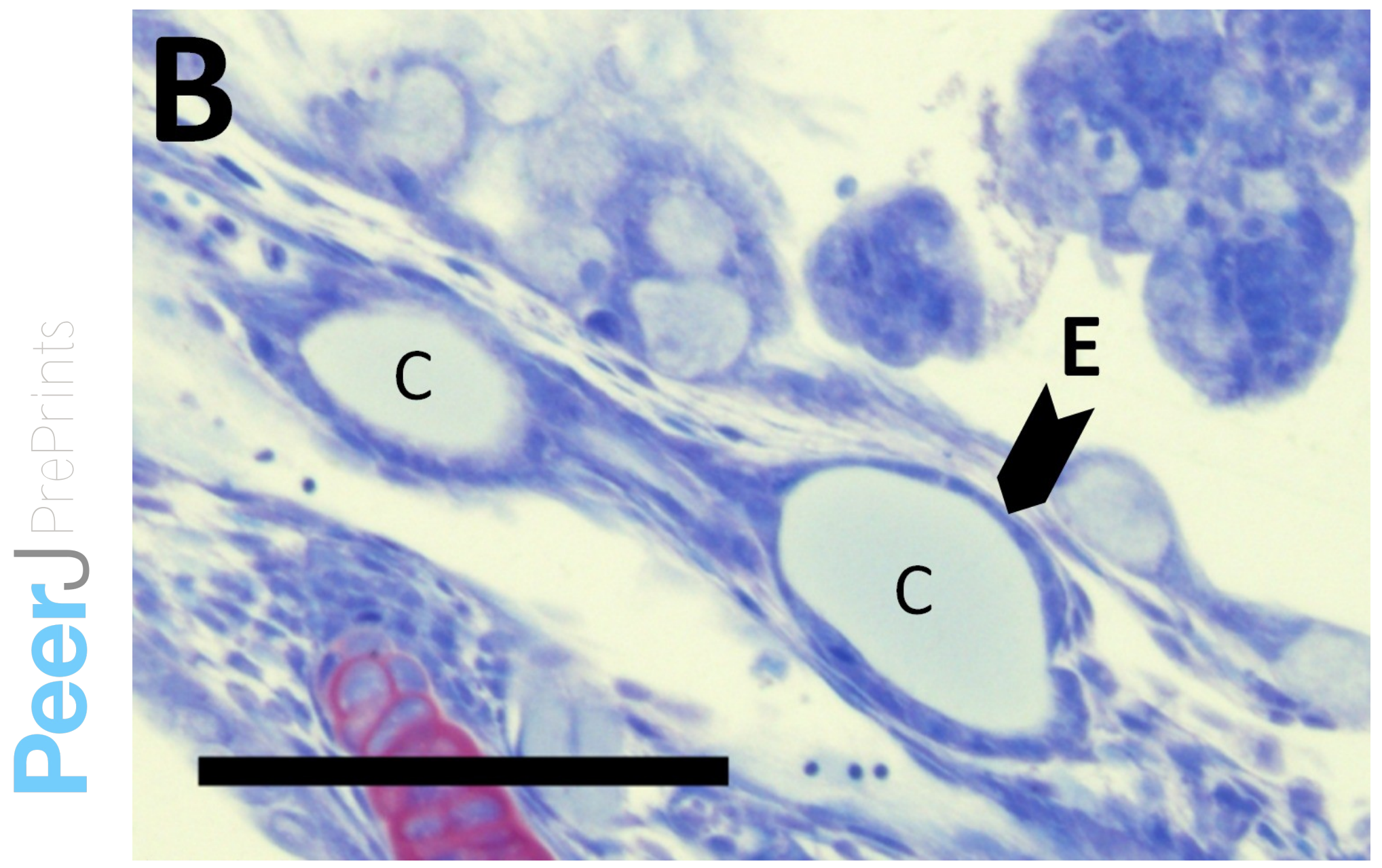

